\title{
Intervención en el castillo de Jimena de la Frontera (Cádiz). Fase I-sector oriental
}

\author{
Francisco Reina Fernández-Trujillo | arquitecto \\ URL de la contribución <www.iaph.es/revistaph/index.php/revistaph/article/view/3751>
}

\section{RESUMEN}

El castillo se sitúa en el límite sureste de la provincia de Cádiz y del parque natural de Los Alcornocales y constituye el asentamiento original de la actual población de Jimena de la Frontera. El conjunto coloniza un promontorio -el cerro de San Cristóbal- ubicado estratégicamente en el paso histórico de la Serranía de Ronda hacia la bahía de Algeciras, circunstancia que ha determinado su ocupación ininterrumpida desde el siglo VIII a. de C. hasta el siglo XIX tras su última reorganización militar en plena Guerra de la Independencia.

Las campañas de investigación realizadas durante la última década han producido importantes hallazgos arqueológicos que han permitido plantear una primera intervención que afecta al sector oriental del complejo, frente sobre el que se recorta el perfil urbano de Jimena y que se encontraba en un deficiente estado de conservación. Los trabajos de restauración siguen un criterio de mínima intervención que prima el valor de antigüedad de las fábricas y la singularidad del conjunto.

Es objetivo de la propuesta extender la visita al exterior del recinto como un itinerario más del parque, descubriendo vistas inéditas del propio castillo, la ciudad y el paisaje. Mimetizado con el propio terreno, el trazado de sendas y pasarelas discurre extramuros entre los fundamentos de las murallas de la Oba romana y la Xemina medieval, procurando introducir un orden necesario en la compleja geometría que definen sobre la ladera. Al enlazar los senderos naturales con los caminos que ascienden desde la trama urbana, el castillo se convierte en la auténtica puerta de Los Alcornocales.

\section{Palabras clave}

Cádiz | Castillos | Intervención en Bienes Inmuebles | Jimena de la Frontera (Cádiz) | Restauración de Patrimonio | 


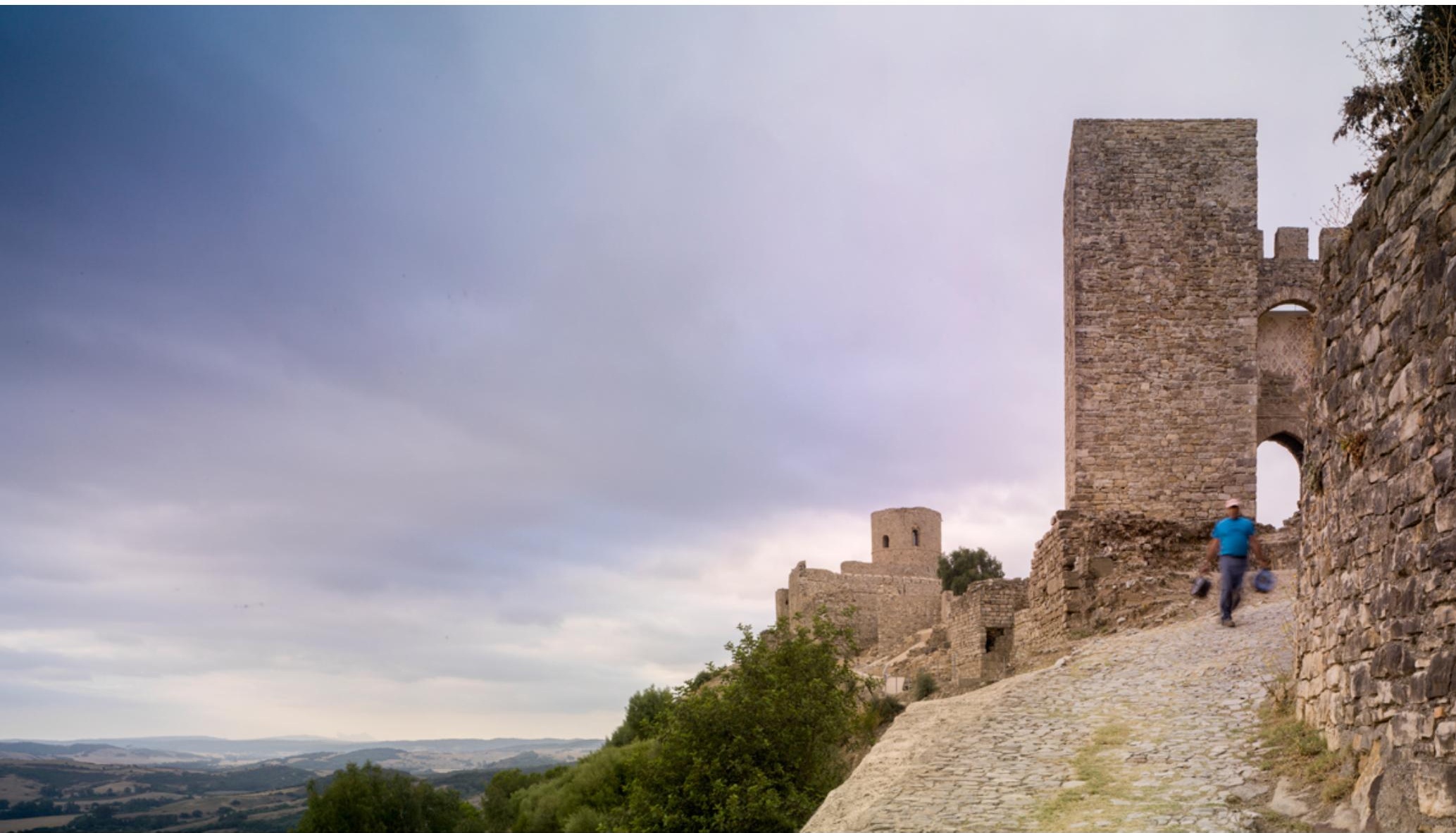

Camino histórico de acceso al castillo | foto Jesús Granada 


\section{ANTECEDENTES}

En el año 2001 se redacta, por encargo de la Consejería de Cultura de la Junta de Andalucía y formando equipo con el arqueólogo Miguel Ángel Tabales, el documento denominado Programa Director de Actuaciones que durante estos años ha vertebrado los trabajos destinados a la investigación, la conservación y puesta en valor del castillo. El programa establece como objetivos básicos la identificación integral de sus límites, las cotas de las distintas ocupaciones, la comprensión espacial y funcional de cada período y, sobre todo, el entendimiento del proceso de transformación.

Las primeras actuaciones se llevaron a cabo en el periodo 2001-2007 impulsadas desde la Consejería de Cultura con el apoyo del Ayuntamiento de Jimena. El artículo publicado en el n. ${ }^{\circ} 60$ de la revista $\mathrm{PH}$-año 2006 - recoge de manera pormenorizada los trabajos realizados en esta etapa inicial. Como primera actuación, la empresa Técnica Cartográfica Andaluza (TCA, S.A.) elaboró un levantamiento planimétrico general del castillo. Desde el año 2002 hasta 2007 se desarrollaron una serie de campañas de intervenciones arqueológicas y arquitectónicas coordinadas entre sí y dirigidas a la obtención de información material relativa a la evolución constructiva del castillo. Los resultados conseguidos han permitido plantear esta primera fase de restauración que afecta al sector oriental del complejo, el más conocido por tratarse del frente sobre el que se recorta el perfil de la ciudad en el paisaje. Las obras han sido promovidas por el Ayuntamiento de Jimena y el Ministerio de Fomento a través del programa $1 \%$ Cultural y han contado con la coordinación de la Junta de Andalucía en la redacción del proyecto y la dirección técnica de los trabajos.

La presente intervención de $1 .^{\mathrm{a}}$ fase ha sido distinguida con la Medalla de Plata 2015 concedida por la Asociación Española de Amigos de los Castillos.

El castillo desde el parque natural de los Alcornocales | foto Jesús Granada

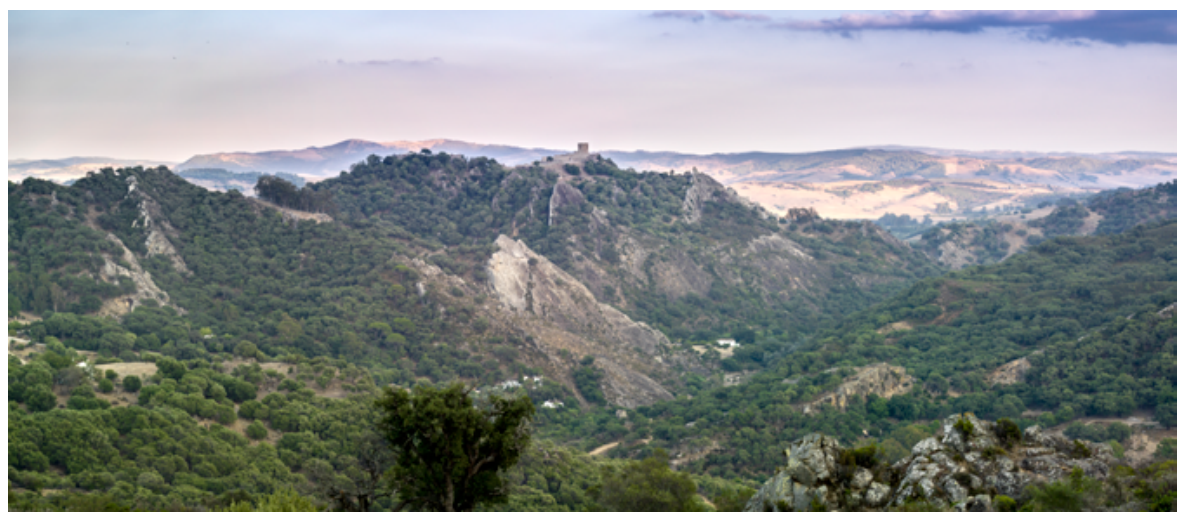




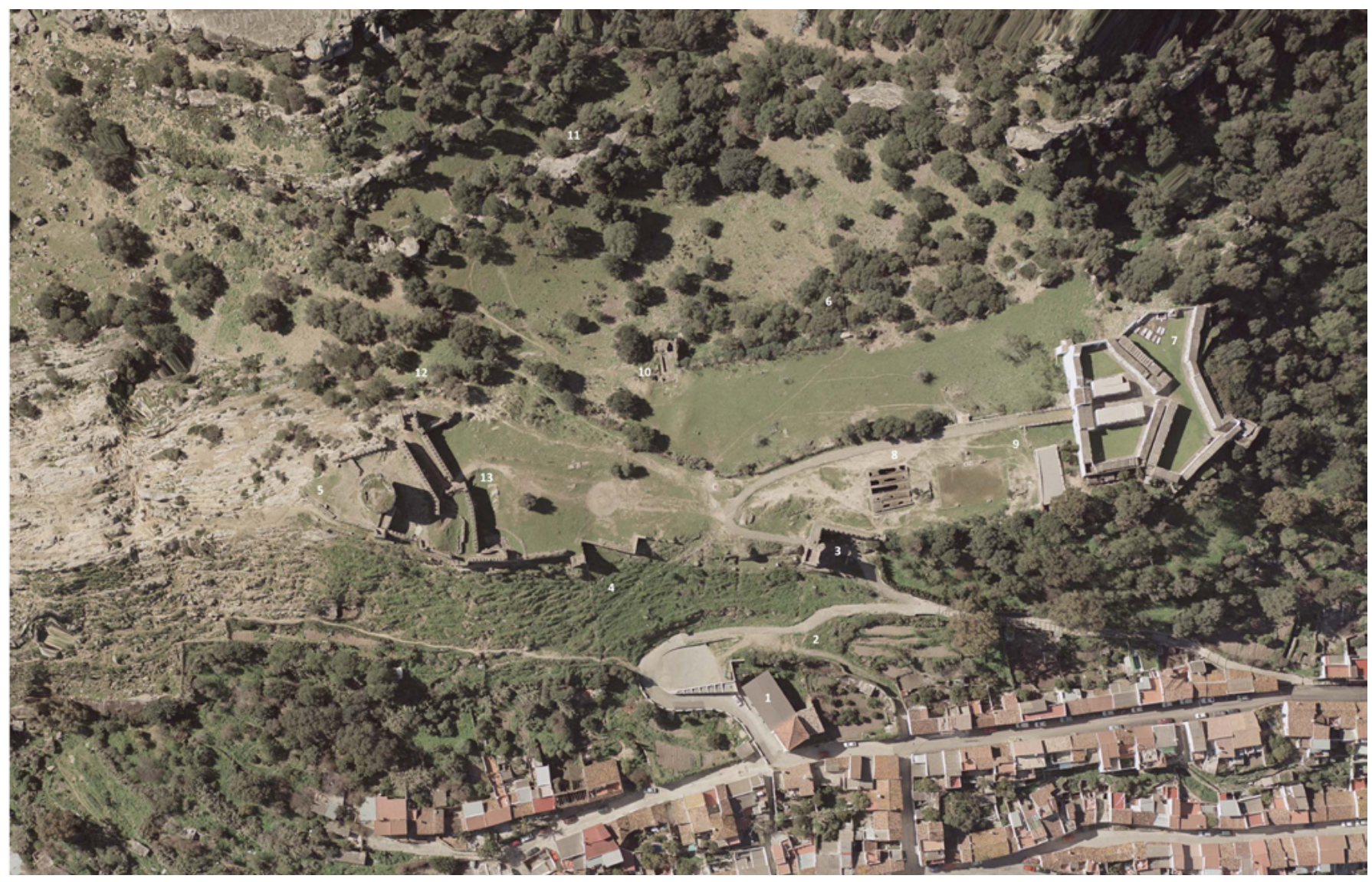

Vista aérea. Estado previo a las obras de 1.a fase: 1. Iglesia de la Misericordia; 2. Camino histórico; 3. Puerta y torre del Reloj; 4. Ladera oriental. Murallas romanas y medievales; 5 . Alcázar. Torre del Homenaje; 6. Ladera occidental. Murallas romanas.; 7. Cementerio; 8. Aljibe almohade; 9. Aljibe medieval; 10. Puerta romana y templo; 11 . Yacimiento mozárabe Baños de la Reina Mora; 12. Camino histórico; 13. Foso medieval del alcázar | foto Técnica Cartográfica Andaluza S.A.

2001: Levantamiento planimétrico general.

2002-2007: Campañas de intervención arqueológica y arquitectónica

(cinco campañas: 2002, 2003, 2004, 2005 y 2006/2007).

$>$ Fase 1 (2010-2014)

2010: Redacción de proyecto de restauración denominado Intervención en el Castillo de Jimena de la Frontera (1. ${ }^{a}$ fase, Sector Oriental).

2012-2014: Ejecución de obras de $1 .^{\mathrm{a}}$ fase.

\section{BREVE RESEÑA HISTÓRICA}

El castillo es el asentamiento original de la actual población de Jimena de la Frontera y contiene los vestigios más antiguos de una dilatada historia. Los primeros indicios de ocupación prehistórica en el sector lo constituyen las pinturas rupestres de la Laja Alta y la cueva de la Chinchilla situadas en el 

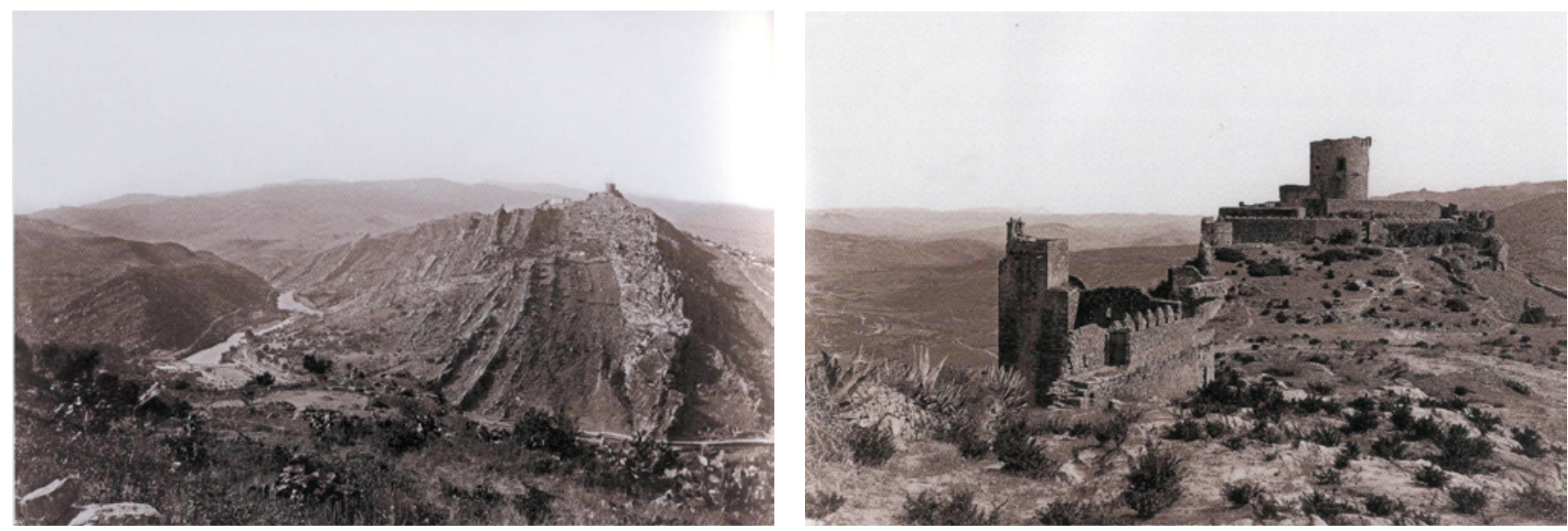

Jimena desde el sur, por G. W. Wilson, década 1870 | fuente GARÓFANO SÁNCHEZ, 2005: 122

Ruinas del castillo, por G. W. Wilson, década 1870 fuente GARÓFANO SÁNCHEZ, 2005: 123 mismo cerro del castillo (SCHUBART, 1993). En el siglo I a. de C. hay evidencias de la existencia de un asentamiento libio-fenicio bajo la denominación de "OBA" en base a las monedas bilingües localizadas.

En la actualidad, destacan por su importancia los restos conservados de murallas, torres, cisternas y templos de época romana (siglos I a. de C. a III d. de C.); aljibes, murallas, viviendas y pozos del período islámico son reflejo del esplendor de la ciudad de Xemina durante el dominio almohade, meriní y nazarí (siglos XII al XV). En el presente, la denominación "castillo" hace referencia al antiguo conjunto urbano amurallado romano e islámico que se conserva en casi todo su perímetro.

La alcazaba o alcázar, muy transformada a comienzos del XIX y abandonada desde entonces, se sitúa al sur sobre una de las elevaciones del cerro, protegida por un foso en $\mathrm{V}$ tallado en la roca que la separa del resto del recinto. La fortaleza principal defiende la torre del Homenaje, bastión nobiliario levantado a fines del siglo XV o inicios del XVI durante el período de dominio del duque de Medina Sidonia tras la conquista a los nazaríes. El aspecto actual de sus muros, aspilleras y foso obedecen a la adecuación del antiguo alcázar a las nuevas necesidades derivadas del uso de la artillería y la fusilería y que tenían por objeto asentar una guarnición durante la Guerra de la Independencia. Esta operación supuso el desmonte de los lienzos medievales y modernos de los que son vestigios el foso almohade y la torre del Homenaje. Actualmente la torre aparece exenta y destacada sobre el promontorio, pero en su contexto original se encontraba enlazada a la muralla perimetral mediante dos lienzos hoy conservados sólo en la base.

En el extremo norte, sobre una elevación similar a la existente en el sur, se ubica el cementerio local. El resto de la antigua villa, accesos y arrabales, ha 


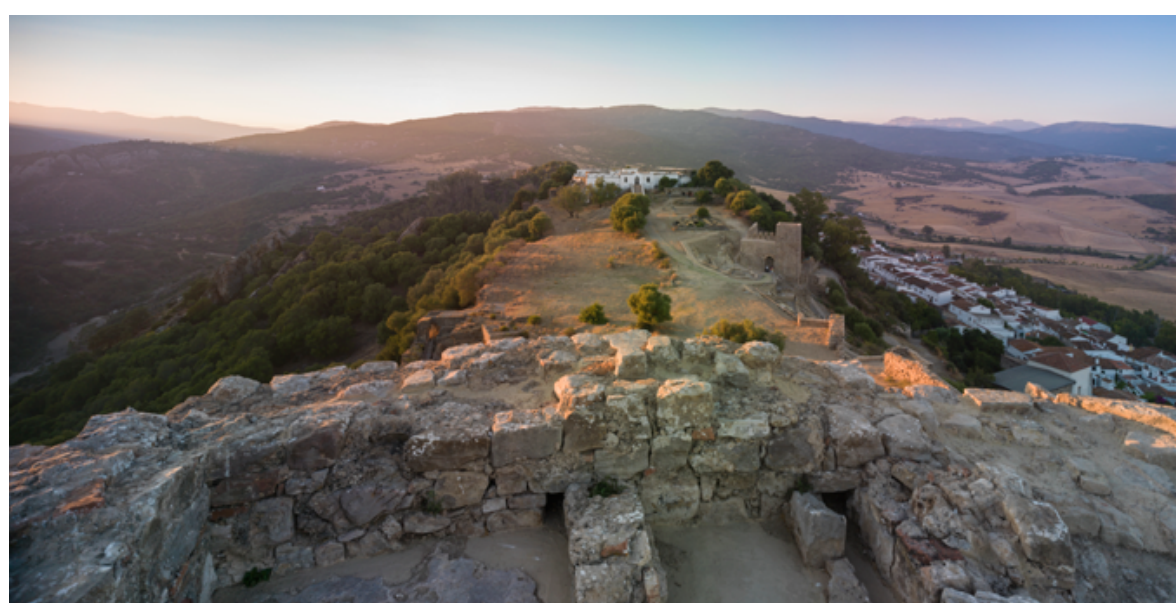

soportado una actividad agropecuaria que ha contribuido a la desaparición y ocultamiento de la ciudad que la ocupó hasta el s. XVI, cuando se abandona el recinto amurallado para extenderse hacia la ladera occidental buscando una mayor relación con el camino y la vega del río Guadiaro. En el centro de la villa se han ido abriendo grandes aljibes desde la época romana, destacando por su volumen el gran aljibe almohade, el recientemente restaurado aljibe de Edad Moderna, y desde los años setenta del siglo XX, la cisterna municipal, en pleno uso.

Un lugar complejo y continuadamente ocupado ha deparado importantes hallazgos durante las fases de actuación realizadas desde el año 2002. En el frente oeste, las bóvedas que soportan una terraza avanzada sobre la ladera construyen la base de un magnífico templo tetrástilo próstilo muy similar a los de la tríada capitolina de la cercana Baelo. La gran edificación del templo formaba parte de un conjunto monumental más amplio centrado en un acceso primitivo (y principal) a la ciudad romana de Oba, que disponía sus edificios principales en las cotas elevadas del promontorio y extendía su caserío a lo largo de la ladera occidental hasta las orillas del río Hozgarganta.

En la ladera oriental se identificaron tres amurallamientos sucesivos -alto y bajo imperial romano (s. I a. de C. y s. III) y almohade-meriní- constatando que el complejo poliorcético llego a ser completamente renovado al menos en tres ocasiones. Destacar el descubrimiento de un edificio imperial labrado con un elegante aparejo y cuya funcionalidad, que debió ser notable, desconocemos. Su compartimentación interior y su posición enfrentada al templo de la cerca occidental nos permiten suponer que frente a ambos se ubicaría un gran espacio abierto, tal vez el foro de la ciudad de Oba. Bajo sus cimientos se localizaron los restos más antiguos del yacimiento, consistentes en un depósito de cerámicas pertenecientes a la Edad del Bronce Final (siglos VIII-VII a. de C.).
El parque natural de los Alcornocales, el castillo, la ciudad de Jimena. Vista desde la torre del Homenaje | foto Jesús Granada

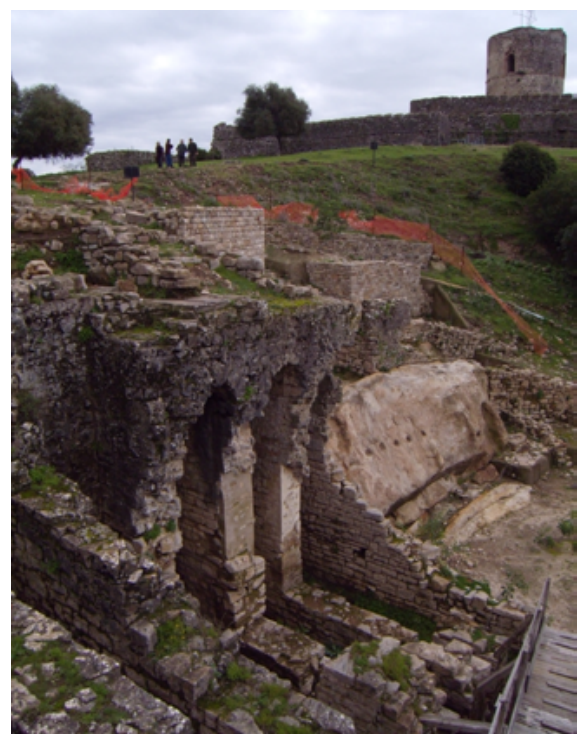

Estructuras del basamento del templo romano adyacente a la puerta primitiva. Sector occidental | foto Estudio Francisco Reina 


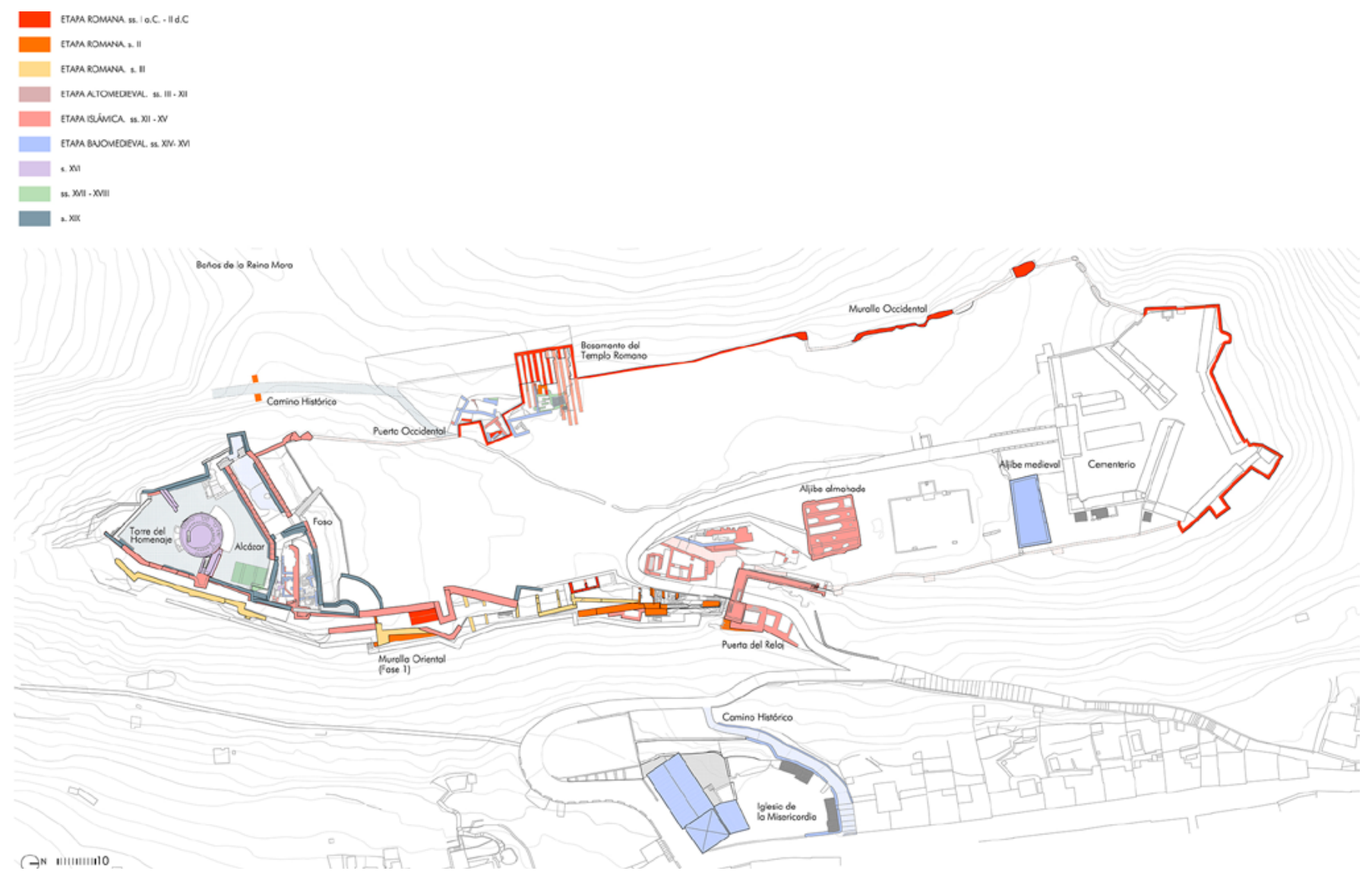

Fases históricas | plano Estudio Francisco Reina

El castillo es por tanto portador de una parte importante de la identidad de la ciudad al haber sido su recinto original hasta hace cinco siglos. La necesidad de afianzar una posición territorial a lo largo de la historia lo ha convertido en un hecho arquitectónico complejo, diverso y de indudable valor patrimonial. Estructuras defensivas de épocas muy distantes en el tiempo que conviven en un mismo área y sobre rasante, infraestructuras hidráulicas de envergadura, puertas y otras piezas urbanas nos desvelan datos acerca del singular carácter de la trama edificatoria que subyace -escondida- a escasos centímetros del manto vegetal que cubre el recinto amurallado.

\section{ESTADO DE CONSERVACIÓN PREVIO AL COMIENZO DE LOS TRABAJOS}

Situado en la frontera entre el territorio del parque y el núcleo urbano, el castillo fusiona rasgos de ambas realidades desdibujando en ocasiones los límites entre lo natural y lo construido. Estas condiciones han favorecido su ocupación gradual con determinados usos o servicios tanto intramuros 
(cementerio, instalaciones urbanas) como extramuros (huertos y corrales que ocupan la ladera nordeste hasta el pie de las murallas).

El perímetro amurallado, construido a lo largo de más de veinte siglos, evidencia en la actualidad importantes discontinuidades y fragmentaciones. Su antigüedad, la acción del hombre, la falta de mantenimiento o el carácter inestable de los terrenos arcillosos sobre los que se apoyan algunos tramos de muralla donde se han producido deslizamientos, son los principales factores que han incidido en conformar su imagen actual. Estas circunstancias ya se reflejaban en el análisis paramental realizado durante las primeras campañas de investigación, donde se destacaba que históricamente determinados sectores habían sido objeto de reparaciones y reconstrucciones.

Las campañas recientemente realizadas descubrieron la potencialidad e importancia del sistema defensivo y la trama urbana ocultos bajo una considerable capa de rellenos. En el caso de las murallas, los vertidos producidos desde el interior de la cerca -y que se encuentran, por tanto, en una situación inestable- han contribuido a desfigurar su imagen en el paisaje.

Tras un exhaustivo trabajo de identificación y análisis constructivo de los distintos aparejos murarios -hasta 21 registros diferentes-, en el proyecto se singularizaban los principales daños y patologías para cada tipo de fábrica. Los más generalizados se debían a pérdida de piezas y falta de consisten-

Estado previo. Ladera oriental (izquierda) y detalle de restos del edificio imperial romano del s. I a. de C. (derecha) | fotos Estpudio Francisco Reina
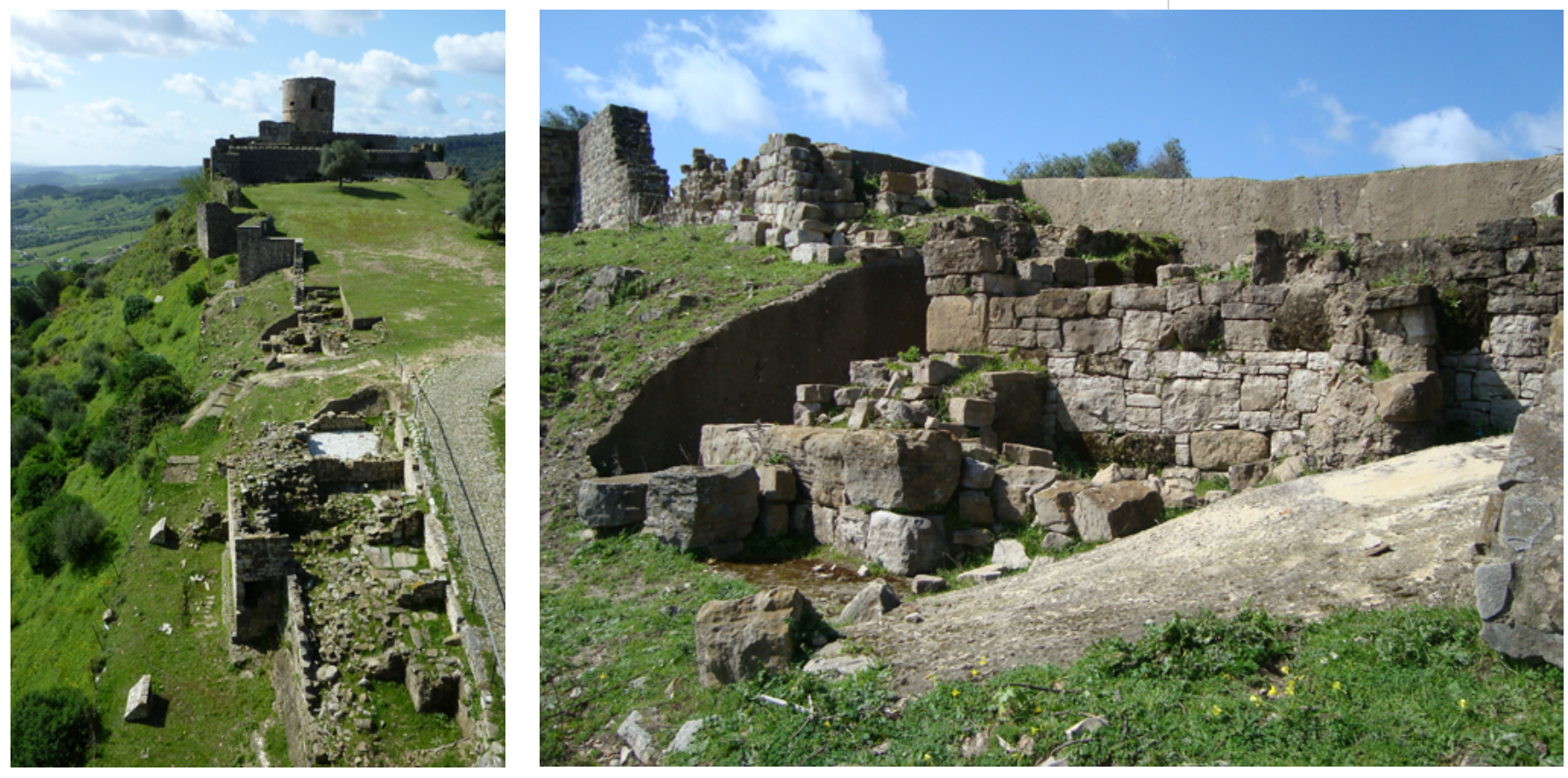
cia -incluso disgregación o inexistencia- de morteros de cal en las juntas. Las pérdidas puntuales de material se habían producido por acciones térmicas, erosión del viento (corrasión), acciones del agua en todos sus estados -especialmente por heladicidad e infiltración- de la microflora (colonizaciones de algas y líquenes) y de la vegetación que crece en los paramentos. El estado de la piedra natural variaba según su caracterización petrográfica, función, orientación y altura.

De manera más localizada se apreciaban lesiones estructurales, con aparición de fisuras, grietas, desplazamientos, desplomes, etc., en algunos casos acentuadas por la acción de raíces vegetales. En los tramos de murallas romanas situados extramuros se observa la desaparición de forros externos de fábricas de mampostería o sillar, dejando a la vista el material de relleno o emplectom de menor consistencia y, por tanto, fácilmente erosionable.
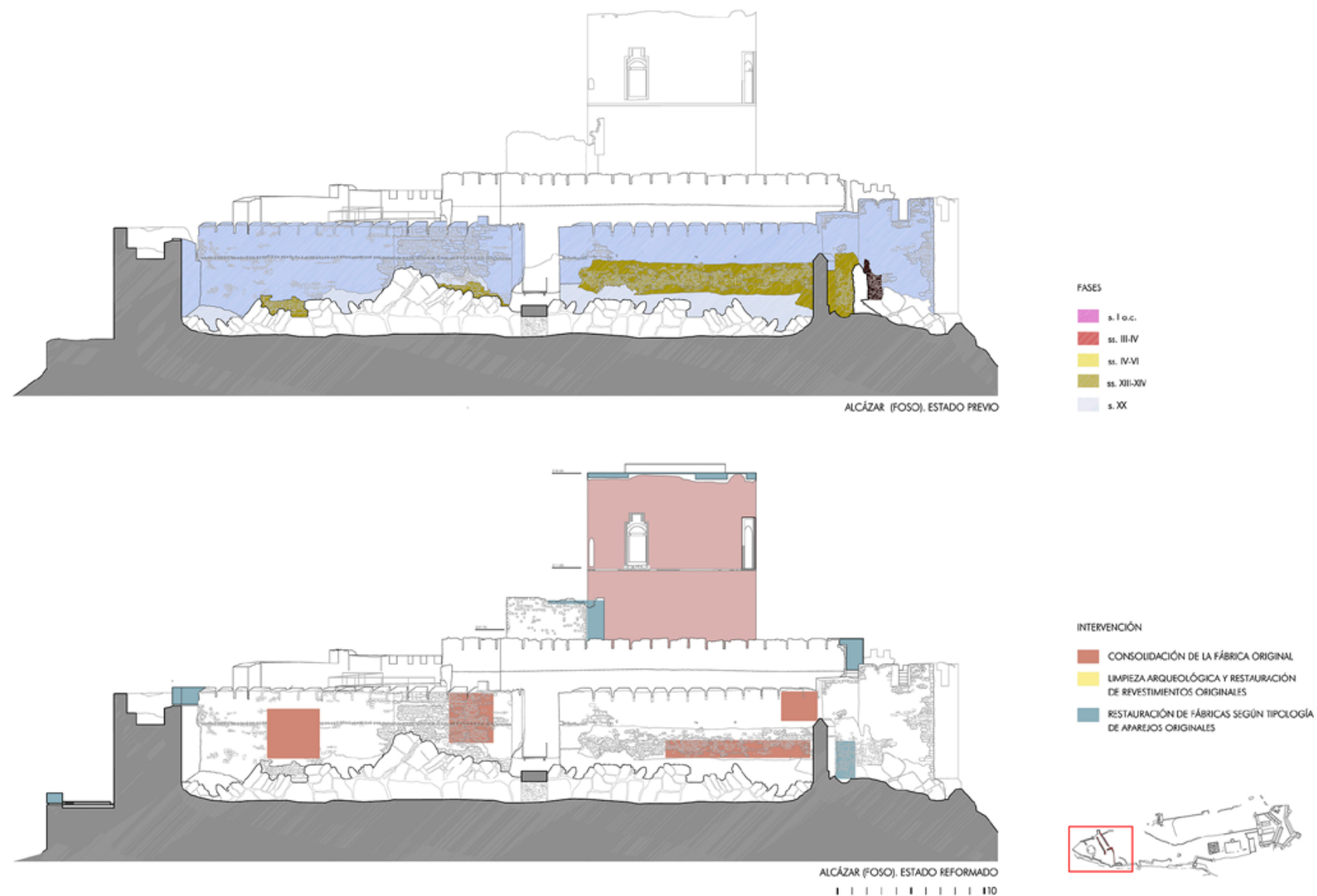
Destacar finalmente los daños en las fábricas producidos por la acción humana: construcción de elementos añadidos, cegamientos, apertura de huecos, actos puntuales de vandalismo con desmontaje parcial de elementos, expolio o restauraciones en las que se habían empleado materiales inadecuados. En relación con los pavimentos, presentaban pérdidas por expolio, por la acción de animales o por acción directa del agua de lluvia, debida en parte al mal funcionamiento o la desaparición de sistemas de canalización y drenaje.

Los revestimientos paramentales se encontraban prácticamente perdidos. Sólo se detectaron restos de estucados con mortero de cal en algunos sectores de la muralla bajomedieval oriental -dibujos geométricos esgrafiados- y en la puerta del Reloj, acceso principal a la medina islámica que fue estudiada por el restaurador Carlos Núñez Guerrero. Sobre la puerta se conservaban algunos fragmentos de pintura mural esgrafiada sobre estuco que
Puerta del Reloj. Estado previo | foto Estudio Francisco Reina

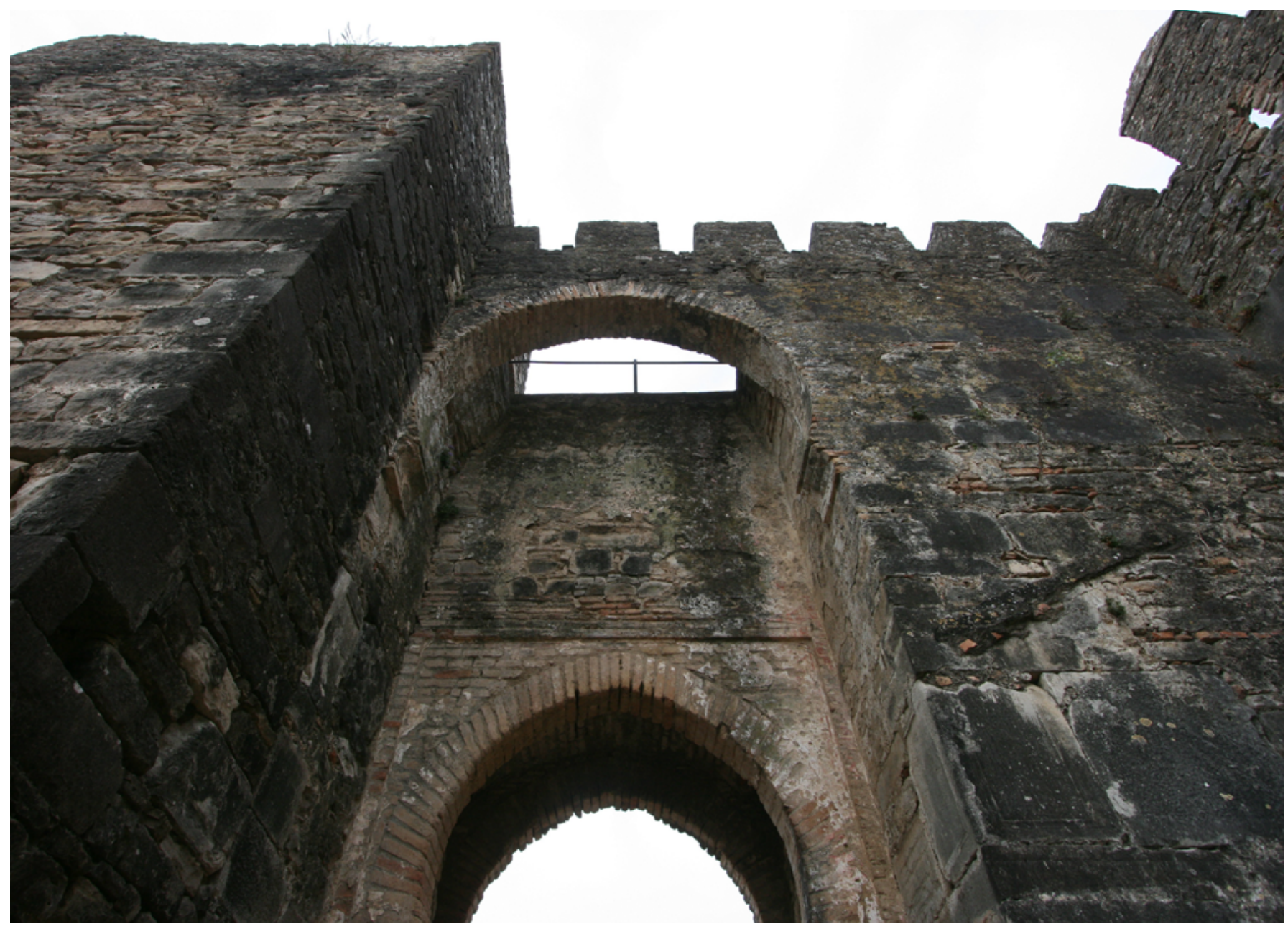


Vista de los trabajos de limpieza arqueológica. Sector oriental | foto Estudio Francisco Reina

formaban parte de una decoración de arquitecturas, lacerías y una sebka en tonos rojos y amarillos. La acción de las condiciones medioambientales y las filtraciones pluviales que se producían a través del muro soporte favorecieron el crecimiento de diferentes colonias de microflora, reconociéndose la presencia de algas y líquenes que prácticamente ocultaban la decoración. Las oscilaciones de humedad habían producido sobre las superficies una cristalización de los minerales diluidos en el agua, formándose costras carbonatadas de tono oscuro que ocultaban las superficies decoradas. Destacar que las lagunas y faltas ocupaban aproximadamente un $75 \%$ de lo que fue la decoración original. Así mismo, los revestimientos conservados presentaban abofados, fisuras y desprendimiento parcial del soporte, según zonas.

\section{TRABAJOS ARQUEOLÓGICOS INICIALES}

Al inicio de las obras y en el ámbito de la actividad arqueológica preventiva de control de movimiento de tierras -trabajos dirigidos por los arqueólogos Raquel Utrera Burgal y Juan Miguel Pajuelo Sáez bajo la coordinación de Miguel Ángel Tabales- se realizó la retirada de vertidos y materiales de relleno de las áreas afectadas por la actuación.

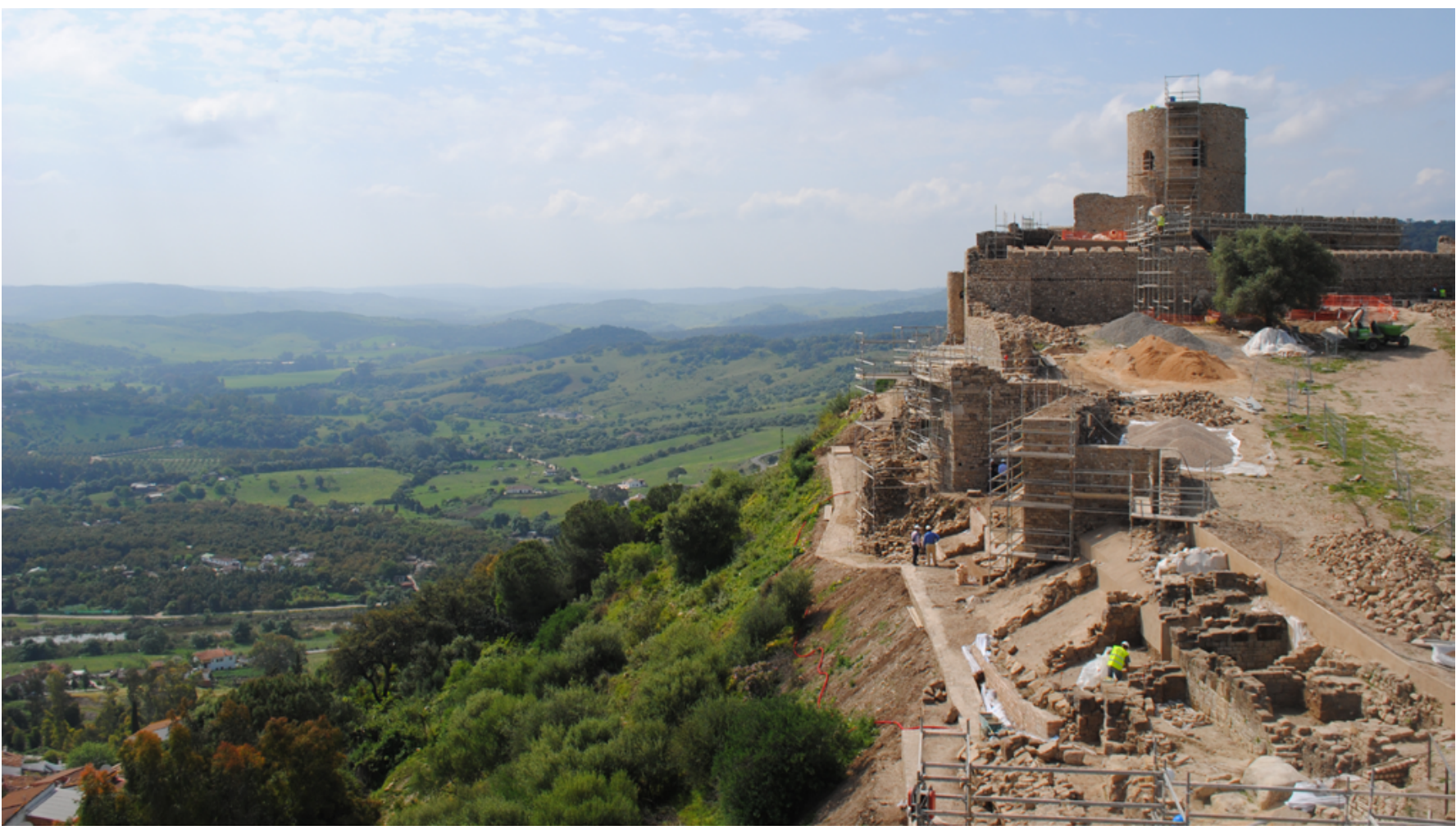




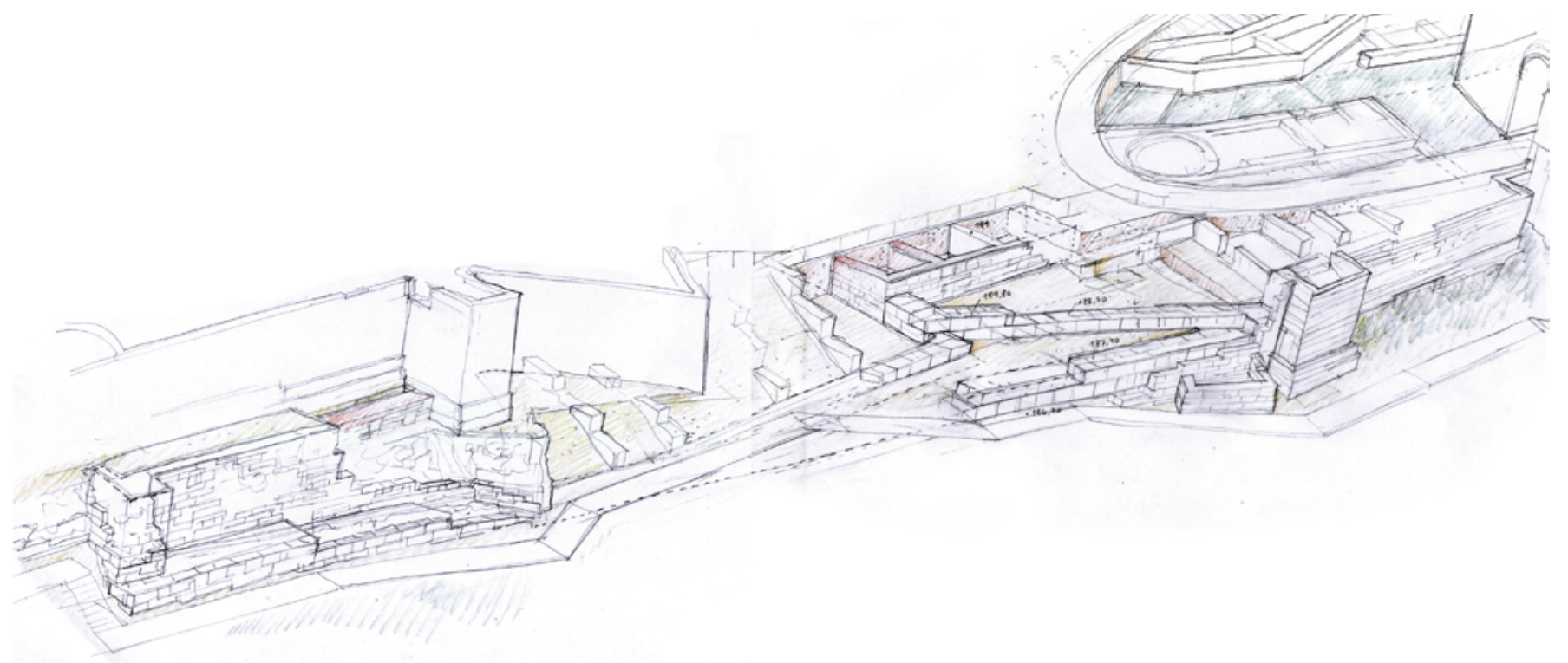

Fases históricas. Croquis de las estructuras investigadas en la ladera este. Superposición de murallas romanas (s. I a. de C. a s.III) y muralla

Extramuros de la ladera oriental quedaron al descubierto restos de lienzos y murallas romanas (s. I a. de C. a s.ll torres pertenecientes a las fases tardorepublicana-imperial romana (siglos I a. de C. a II d. de C.), bajoimperial (s. III) e islámica (s. XII-XV) que han complejizado la lectura de los límites históricos del recinto. En las cotas topográficas más bajas el sistema defensivo sufrió innumerables replanteos hasta su ocultamiento definitivo. La ciudad medieval se ciñe al perímetro actual dejando al exterior los muros romanos que son utilizados en numerosos sectores como antemuro o simplemente como cimentación de los nuevos lienzos. Se distinguen entre sí a simple vista por su aparejo, destacando los más antiguos - de opus vittatum- por la perfección de su labra. Los más modernos -bajo imperiales y tardíos- refuerzan a las estructuras anteriores y normalmente adquieren una posición más externa. Más allá de la refortificación del enclave, reflejan una plena reurbanización de la ciudad de Oba. Destacar que en la ladera occidental se conserva un tramo de más de cien metros de longitud con alzados que llegan a alcanzar cinco metros de altura, datos que hablan de la importancia y singularidad del enclave en nuestro entorno regional.

En algunos sectores de estas murallas romanas se aprecian fallos de estabilidad con caída de lienzos, desplazamiento de alineaciones, así como operaciones de reforma, reparaciones y reconstrucciones. Los movimientos del perímetro han obedecido al refuerzo del sistema que, en situaciones concretas, han llegado a buscar puntos de apoyo en edificaciones intramuros. La ladera oriental refleja como ninguna otra zona del castillo los dos mil años de una historia compleja en la que la guerra, la destrucción y las necesidades defensivas fueron protagonistas. Destacar que una parte de este sector se 


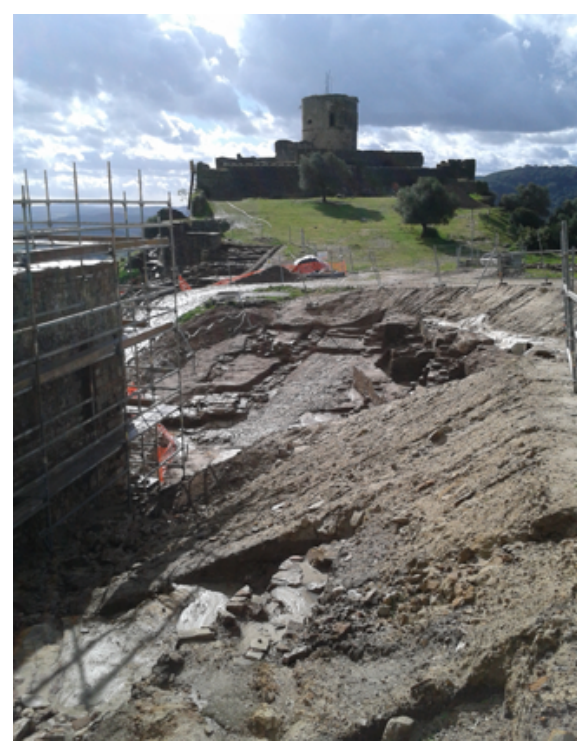

Investigación arqueológica en el entorno de la puerta del Reloj. Trama urbana medieval | foto Estudio Francisco Reina encontraba muy afectada por la instalación del sistema de abastecimiento urbano procedente del depósito ejecutado en la segunda mitad del siglo XX, cuyo trazado dañó puntualmente muros y eliminó registros estratigráficos por lo que fue corregido durante las obras.

Intramuros, a escasos centímetros del nivel actual del terreno, aparecen los restos superpuestos de viviendas y calle medievales, normalmente sobre cimentaciones de estructuras romanas. En el entorno inmediato a la puerta del Reloj-acceso principal al castillo- la retirada superficial de los rellenos de arenisco procedentes de la construcción del depósito municipal dejó al descubierto los restos de estructuras de viviendas y la calle principal que desemboca en recodo en la referida puerta, resultado de múltiples reformas tardomedievales y modernas. Esta calle, con orientación norte-sur, está pavimentada con cantos de río y flanqueada a ambos lados por construcciones que se conservan en distinta medida. Lo que observamos es un fragmento del urbanismo de la medina islámica, parcialmente reformado a fines del XV e inicios del XVI. Tras la conquista y las sucesivas guerras civiles se produjo paulatinamente el abandono del recinto amurallado y el expolio de sus edificios, extendiéndose entonces la ciudad hacia la ladera oriental. Sólo durante la Guerra de la Independencia, en otoño de 1811, se realizaron reformas en la muralla, consolidándose desde entonces la imagen de planicie yerma intramuros actualmente reconocible. Se trata de una zona de enorme interés que hasta ahora no había sido investigada, lo que supone una mejora cualitativa en la puesta en valor del castillo.

En el alcázar se realizó la excavación de la plataforma inferior donde aparecieron estructuras domésticas pertenecientes al período islámico con reformas posteriores. Se identifican hasta tres niveles superpuestos delimitados por dos tramos de muralla. En el frente oriental se investigan los restos de una torre circular islámica con escalera de subida al adarve, forrada y dotada de troneras vigía en 1810. En un segundo nivel, aparecen dos viviendas con un pasaje exterior, limitada por las estructuras de un aljibe. Este sector fue rellenado en 1811 y sobre el nivel resultante se construyó un lienzo de muralla que permaneció volcado hasta la campaña arqueológica de 2005. A destacar la incompatibilidad de las estructuras inferiores con el foso, situado tras la muralla, que las corta. Probablemente su apertura deba fecharse a fines del siglo $X V$ durante las campañas que terminaron con la conquista castellana de Xemina en 1456, sin que pueda descartarse una cronología algo posterior, durante el período en que la fortaleza perteneció al duque de Medina Sidonia.

Por sus singulares condiciones, la torre del Homenaje ha sido también objeto de un estudio específico realizado por la arqueóloga Cristina Vargas Lorenzo, dirigida por Miguel Ángel Tabales Rodríguez. Como resultado de las investigaciones, destacar el carácter monofásico de la torre, construida 


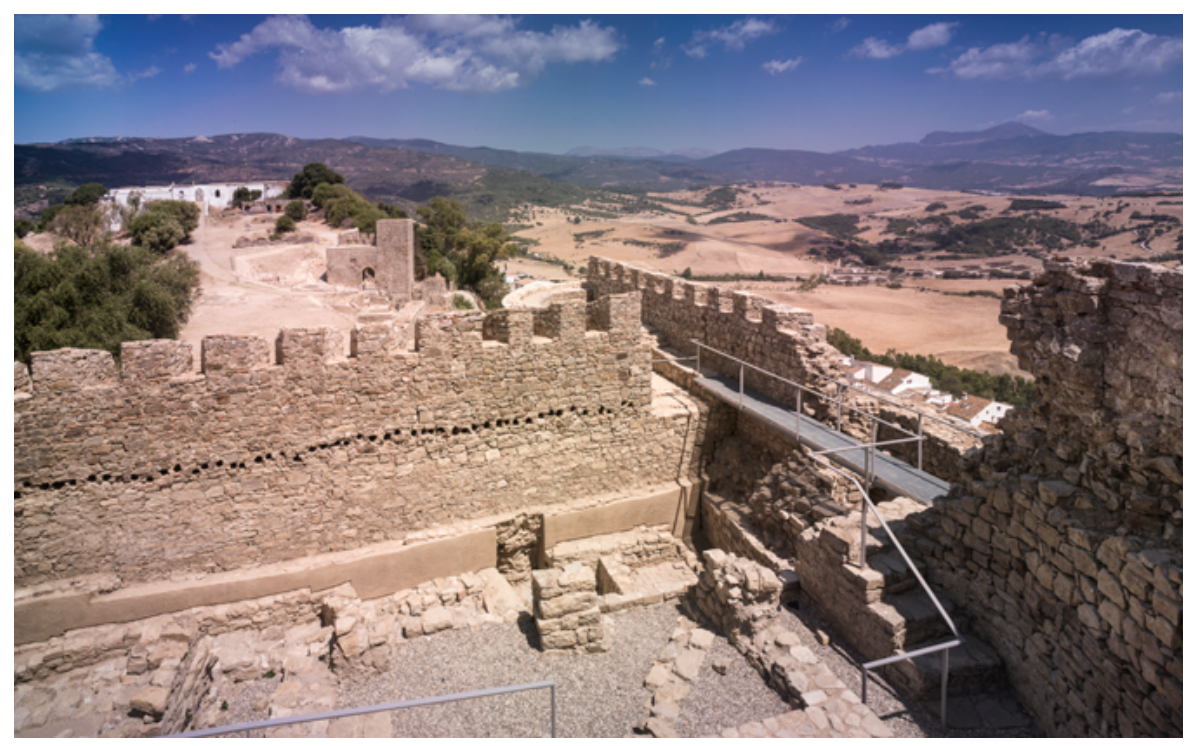

sobre una alcazaba previa durante el S. XVI y las transformaciones más significativas realizadas con motivo de la fortificación del alcázar durante el siglo XIX para su adaptación a la maquinaria armamentística en el contexto de la invasión napoleónica. En esta fase se produce el cegamiento de la puerta original, muy expuesta al estar situada en el nivel superior $-y$ principal- y su sustitución por un hueco practicado en el nivel intermedio, en el ámbito de embarque de las escaleras donde el muro de cerramiento presenta un menor espesor. Así mismo, a esta fase parece corresponderse la apertura de planta abocinada practicada en la cámara inferior en la orientación norte, posiblemente vinculada al uso de este espacio desde el patio de armas -puede que como almacén de material artillero, polvorín, etc.-, entrada que estaría precedida de una construcción adosada de planta semicircular paralela a la torre y cuya huella en el pavimento fue hallada durante las obras.

En la planta principal, fue localizado el nivel de pavimento original (s. XVI) y su reparación en el s. XIX, datos esenciales para los trabajos de restauración. En cubierta se han estudiado las transformaciones producidas durante la Guerra de la Independencia para su adaptación artillera, con incidencia en el almenado y el pavimento. El almenado original fue sustituido por nuevas protecciones adaptadas para fusilería y cañones, similares a las ejecutadas en la totalidad del recinto del alcázar. En la cubierta, tras las labores de limpieza, se han documentado los restos pertenecientes a la bóveda de mortero de cal original así como sus reparaciones. Destacar la incidencia que tuvo sobre dicha bóveda el empotramiento de los pilares de apoyo de una plataforma circular de madera destinada a la mejora y nivelación del pavimento para el uso artillero.
Investigación arqueológica en el alcázar. Sector de la plataforma norte | foto Jesús Granada

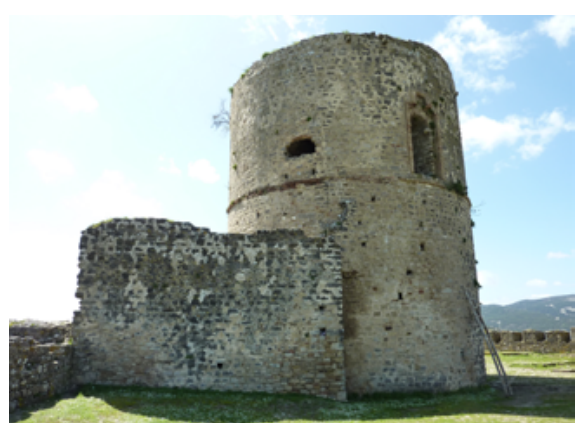

Alcázar. Torre del Homenaje. Estado previo | foto Estudio Francisco Reina 


\section{LA INTERVENCIÓN}

Durante las campañas previas se desarrollaron actuaciones de ajustado

Ladera oriental tras la intervención | foto Jesús Granada

Planta y alzado del ámbito de actuación. Estado final | plano Estudio Francisco Reina alcance, enlazadas entre sí y de inversión muy limitada, que han posibilitado una aproximación progresiva al conocimiento del enclave. Gracias a los datos obtenidos fue posible el planteamiento de esta primera fase de restau-
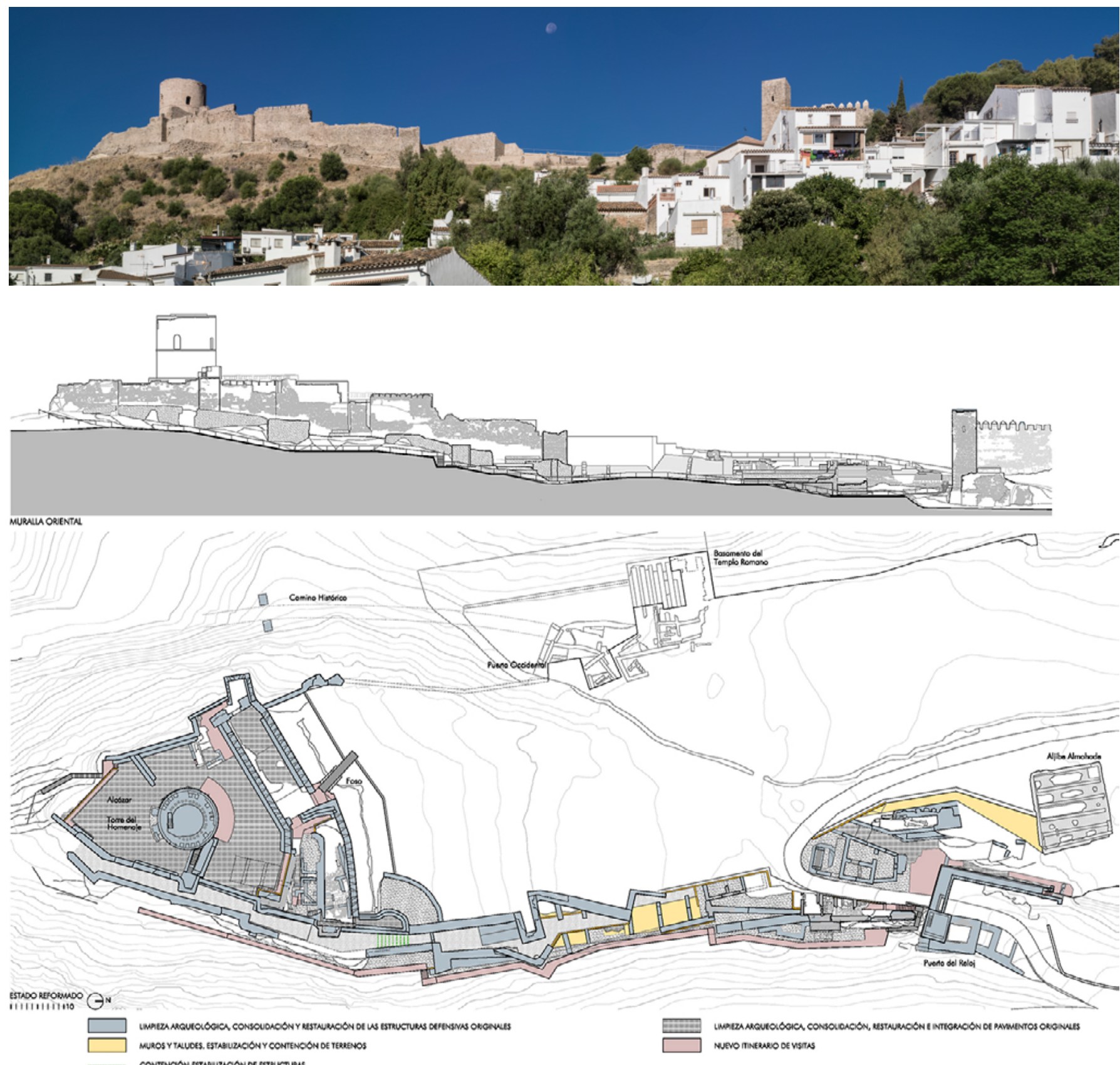
ración y puesta en valor del sector oriental del castillo que se encontraba en un muy deficiente estado de conservación. La actuación realizada ha significado la recuperación del perfil más conocido del castillo y ha tenido una repercusión importante en la escena urbana, dada la entidad de las estructuras restauradas. La lógica elección de este sector en el orden de prioridad ha supuesto posponer otras zonas también investigadas que gozan de un altísimo valor científico y que precisan igualmente actuaciones de conservación, como es el caso de los aljibes medievales o la puerta y el templo romanos situados en la ladera occidental.

Los ingentes trabajos de restauración, que han afectado a la totalidad de las estructuras defensivas en un área de aproximadamente $5.000 \mathrm{~m}^{2}$, han seguido un criterio de mínima intervención que prima el valor de antigüedad de las fábricas y la singularidad del conjunto. La puesta en valor que complementa las actuaciones de conservación se ha dirigido a hacer accesibles las áreas intervenidas.

\section{RESTOS ARQUEOLÓGICOS Y NUEVOS RECORRIDOS, LA LADERA ORIENTAL Y EL ENTORNO DE LA PUERTA DEL RELOJ}

Los restos de murallas romanas e islámicas aparecidos a lo largo del frente oriental dibujan un paisaje arqueológico caracterizado por un intenso proceso de reutilización o reciclaje de elementos.

Cuando visitamos enclaves patrimoniales, inconscientemente buscamos algo reconocible que nos permita dar sentido a nuestra mirada. La investigación arqueológica trata de desvelar las claves basándose en indicios, intuiciones, dataciones, posiciones relativas..., auxiliada siempre por el instrumento del dibujo, poderoso aliado en la búsqueda de relaciones entre las cosas. Estructuras que durante la excavación aparecen superpuestas, yuxtapuestas, limitadas, confinadas entre cortes y taludes, son diseccionadas a través de una precisa representación que indaga las relaciones que se establecen entre ellas y con el resto de preexistencias, proyectando los datos obtenidos más allá del ámbito concreto donde han aparecido. Una vez analizado hasta sus últimas consecuencias lo que allí ocurre, y sin renunciar a la convivencia de todos los momentos posibles, aspiramos con nuestra intervención a introducir un cierto orden que facilite la lectura de lo que observamos.

Aunque tras las labores de limpieza arqueológica el perfil del castillo ha ganado en escala y es ahora más reconocible en el paisaje, su encuentro con el terreno marca una secuencia de límites difusos que se extienden hacia el interior del recinto. El perímetro no lo construye una única muralla sino que adquiere formas diversas para hablarnos de tiempo, de los distin- 

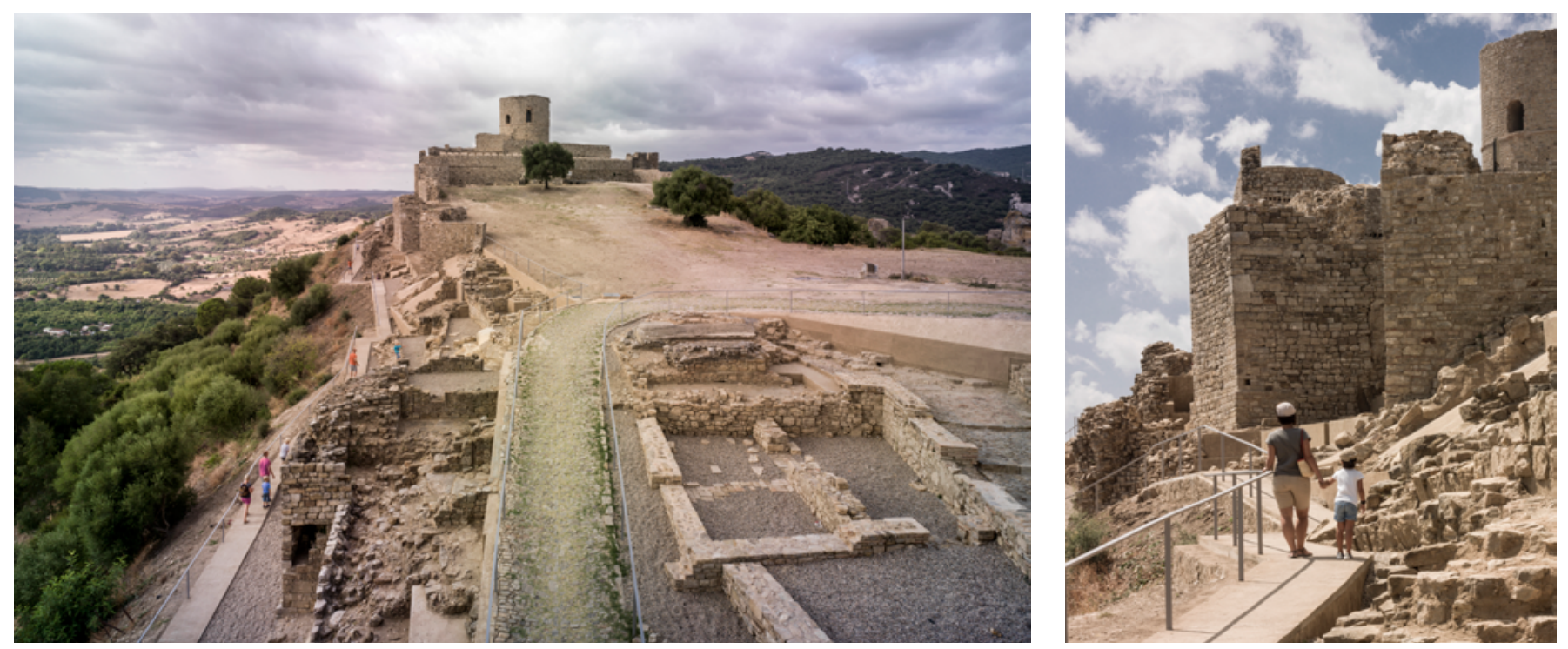

Vistas del sector oriental tras la intervención | fotos Jesús Granada

tos recintos posibles, de las potencialidades y riqueza de lo que aún no ha sido investigado.

Las nuevas sendas se añaden como una banda más a la multiplicidad de alineaciones que durante siglos han ido construyendo el límite oriental. Desde la puerta islámica de Xemina hasta el alcázar acompañan el trazado de todas las murallas e invitan a ser recorridas. Se despliegan en la base de la sección y redibujan, en prácticamente toda su longitud, los caminos trazados por los propios operarios durante las labores de desescombrado o de consolidación, aportando un singular punto de vista, parecido al que debieron tener los constructores de las murallas. Discurren entre los fundamentos de las murallas de la Oba romana y la Xemina medieval, procurando introducir ese orden necesario en las complejas geometrías que aparecen en la ladera. La visita extendida al exterior del recinto se convierte en un itinerario más del parque, descubriendo vistas inéditas del propio castillo, de la ciudad y del paisaje. Al enlazar los senderos naturales con los caminos que ascienden desde la trama urbana, el castillo se convierte en la auténtica puerta de Los Alcornocales.

La fragilidad material de los restos arqueológicos ha obligado a una cuidadosa cirugía para garantizar su preservación. La diversidad de estados de conservación de las estructuras ha sugerido una actitud paralela en la restauración, singularizando el alcance de los tratamientos de consolidación. Se defiende la autenticidad de estas arquitecturas, evitando en lo posible las restituciones y valorando en la misma medida tanto los forros conservados como los rellenos interiores (emplecton) que configuran masas de ricas texturas y fuerte plasticidad visual. Cuando la fábrica está completamente 

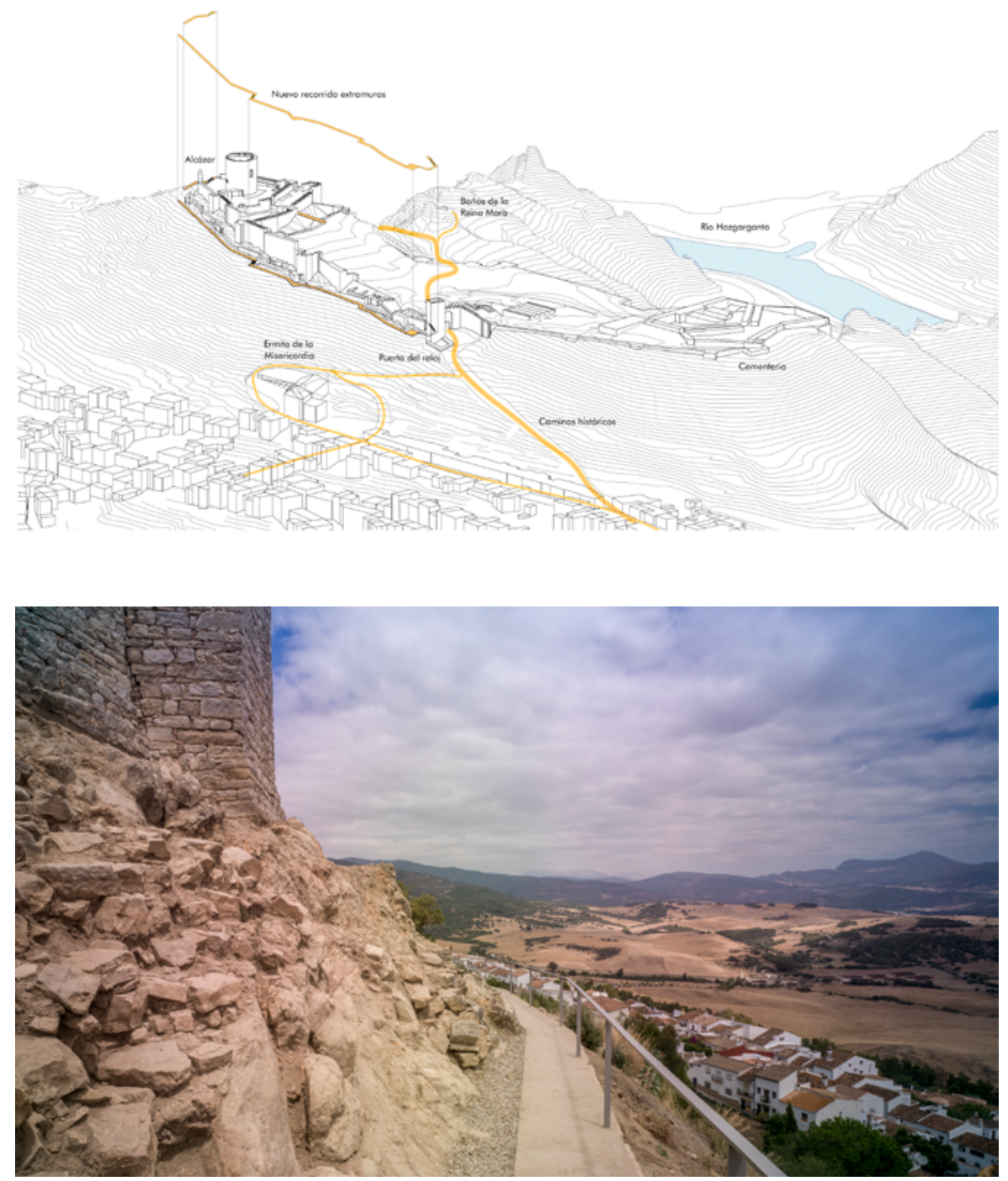

Esquema general. Relación con la ciudad y el entorno del parque natural | plano Estudio Francisco Reina

Frente oriental, nuevas sendas de visita. A los pies de la ladera, la ciudad de Jimena | foto Jesús Granada

ausente, cobra valor la talla en la roca, el relieve necesario para acomodar las primeras hiladas que sólo insinúa la línea desaparecida.

Todo lo demás, lo que aportamos -contenciones, alineaciones, pasarelas, barandillas- ha de mantenerse en un segundo plano. En el tratamiento de límites y encuentros nos auxiliamos constantemente de la geometría que busca acuerdos para que la mirada se deslice y evite detenerse en lo anecdótico o en lo carente de interés. Se investiga el nivel de uso original y se hace coincidir en lo posible con las nuevas sendas que resuelven los recorridos mimetizadas con el propio terreno. 
Frente oriental y extremo sur, entorno del alcázar | foto Jesús Granada
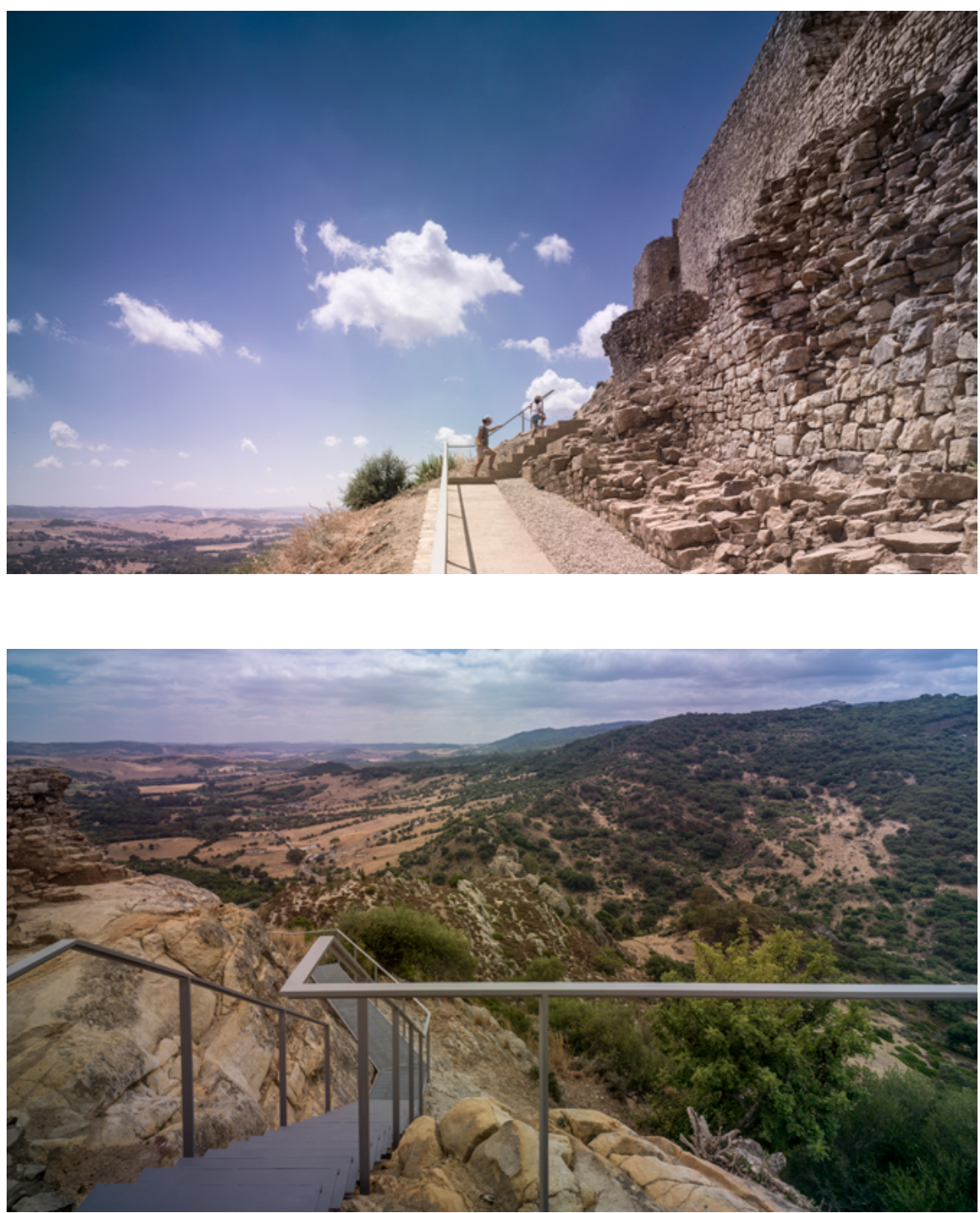

Extremo sur, ascenso a la plataforma del alcázar | foto Jesús Granada
En el extremo sur del cerro, frente al alcázar, las murallas extramuros han desaparecido y también lo hace el sendero en el contacto con la roca natural. Sólo permanecen algunos tramos de barandillas que, estratégicamente colocados, nos guían hacia la banda oeste donde el alcázar ha perdido un tramo de la muraIla. En este punto, un sistema de pasarelas y escaleras metálicas acomodados al perfil de la roca natural nos devuelve la mirada al valle del río Hozgarganta, a la vez que asciende hacia la plataforma pavimentada del patio de armas.

Se ha cuidado el diseño y acabado de los nuevos elementos que facilitan los recorridos para que acompañen al visitante con discreción, integrados en el paisaje, sin apenas destacar frente a las estructuras históricas. Las pasare- 

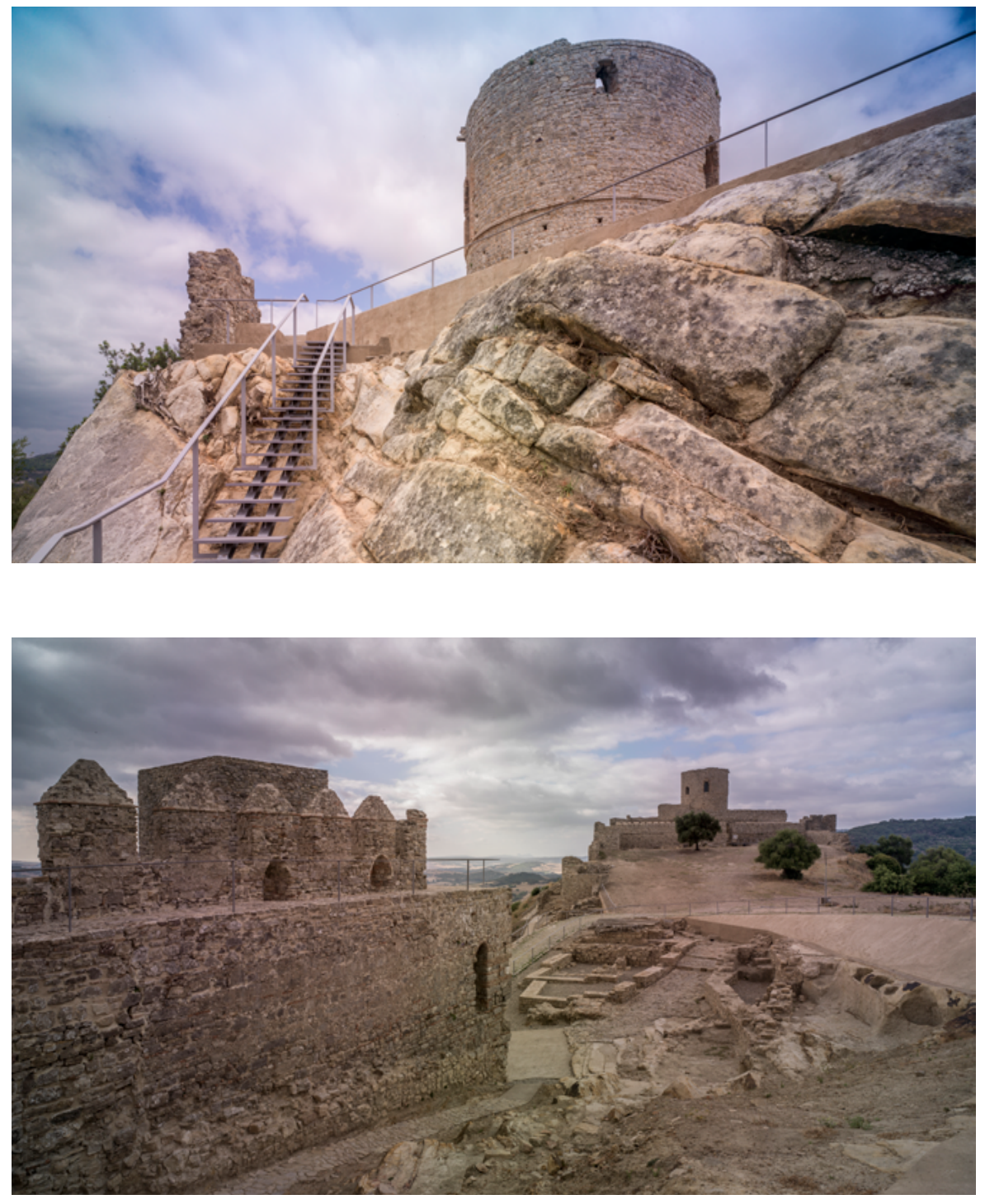

Extremo sur, ascenso a la plataforma del alcázar | foto Jesús Granada

Entorno de la puerta del Reloj. Trama urbana medieval | foto Jesús Granada

las y escaleras metálicas aparecen sólo cuando es estrictamente necesario, con levedad, aprovechando espacios ajustados, semiocultas entre muros o rocas, sugiriendo recorridos que invitan a ser explorados. Del mismo modo, se vigila el impacto de protecciones y barandillas calibrando el perfil metálico utilizado para evitar su visión desde la lejanía. Esta actitud ha requerido un intenso seguimiento durante la fase de replanteo y ejecución de los trazados, donde se han definido y ajustado las posiciones concretas de los elementos que componen el nuevo sistema, con especial atención a sus apoyos que se ubican en zonas de relleno o lagunas para evitar el contacto con las preexistencias. Los senderos de paso incorporan las infraestructuras necesarias para el equipamiento de un sistema de iluminación monumental. 

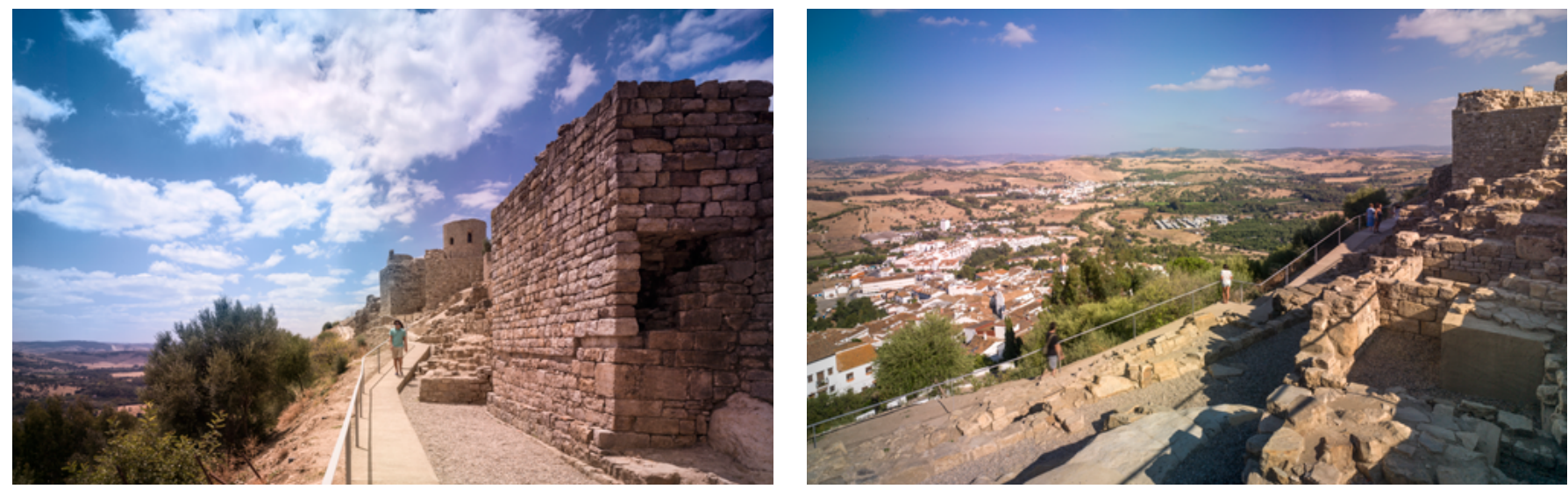

Vistas del frente oriental. Jimena | fotos Jesús Granada

Algunas contenciones garantizan la estabilidad de tierras y estructuras. Superficies abstractas y volúmenes que construyen fondos y dirigen líneas donde antes existían límites. Se ha cuidado especialmente su aspecto neutro empleando en la fabricación de hormigones y morteros tierras seleccionadas del lugar. En el entorno de la puerta del Reloj, algunos muros -pocos- se significan mínimamente para contener los pavimentos medievales, para entender la espacialidad arquitectónica, la configuración volumétrica de una incipiente trama urbana. Los planos horizontales reciben sencillos tratamientos de áridos o tierras compactadas con cal que distinguen zonas pavimentadas o reproducen planos de usos. Finalmente, las barandillas y pasarelas que delimitan el camino que asciende hacia el cementerio rematan la presentación del yacimiento y predisponen a su contemplación.

Se ha construido una nueva escenografía en la que se presentan los hallazgos, donde se sugieren las potencialidades del lugar, la extensión del resto del yacimiento tras nuestras contenciones, la importancia de lo que aguarda bajo el suelo aún no investigado. Como resultado, aparece un castillo que se asienta con naturalidad en la ladera, con una componente más orgánica reforzada por los nuevos recorridos exteriores. En la intervención realizada en 2002, la consolidación estructural de un bastión de la muralla oriental en una ladera absolutamente desdibujada por los vertidos reclamaba atención sobre el perfil del castillo en el paisaje. Ahora, gracias a los trabajos arqueológicos y la presentación de los hallazgos, se consigue la continuidad del frente oriental tras eliminar únicamente rellenos y añadidos, consolidando los restos que aparecen, restituyendo alineaciones mediante el trazado de las nuevas sendas. Con el tiempo la naturaleza irá puliendo, desgastando, atemperando las aristas de las contenciones, dulcificando o apagando los tonos de lo que ha sido recientemente restaurado para transformarlo todo, poco a poco en ruina, como es la forma natural del castillo en el paisaje. 


\section{LOS TRABAJOS DE CONSERVACIÓN Y RESTAURACIÓN}

La actuación realizada se ha guiado por un criterio de mínima intervención que evita en todo momento el protagonismo de los nuevos tratamientos o aportaciones. A continuación se describen algunas de las técnicas de construcción y restauración empleadas:

$>$ En general, en muros y fábricas, tras la aplicación de biocida y posterior limpieza con agua destilada a presión controlada al objeto de conservar las pátinas originales, se ha ejecutado un resanado general de los morteros de llagas utilizando morteros de cal y arena -del lugar- rehundidos para no alterar la fisonomía de las fábricas cuyo aspecto lo definen principalmente los sillares y mampuestos de piedra al haber perdido la capa de revestimiento original. Cuando ha sido imprescindible la restitución puntual de fábricas - para garantizar su estabilidad o dotar de una mínima consistencia formal a las estructuras en situación más precaria-, y en función de su aparejo, se ha adoptado un criterio de tratamiento neutro de los nuevos materiales.

Muralla norte del alcázar y foso, tras los trabajos de restauración | foto Miguel Ángel Tabales

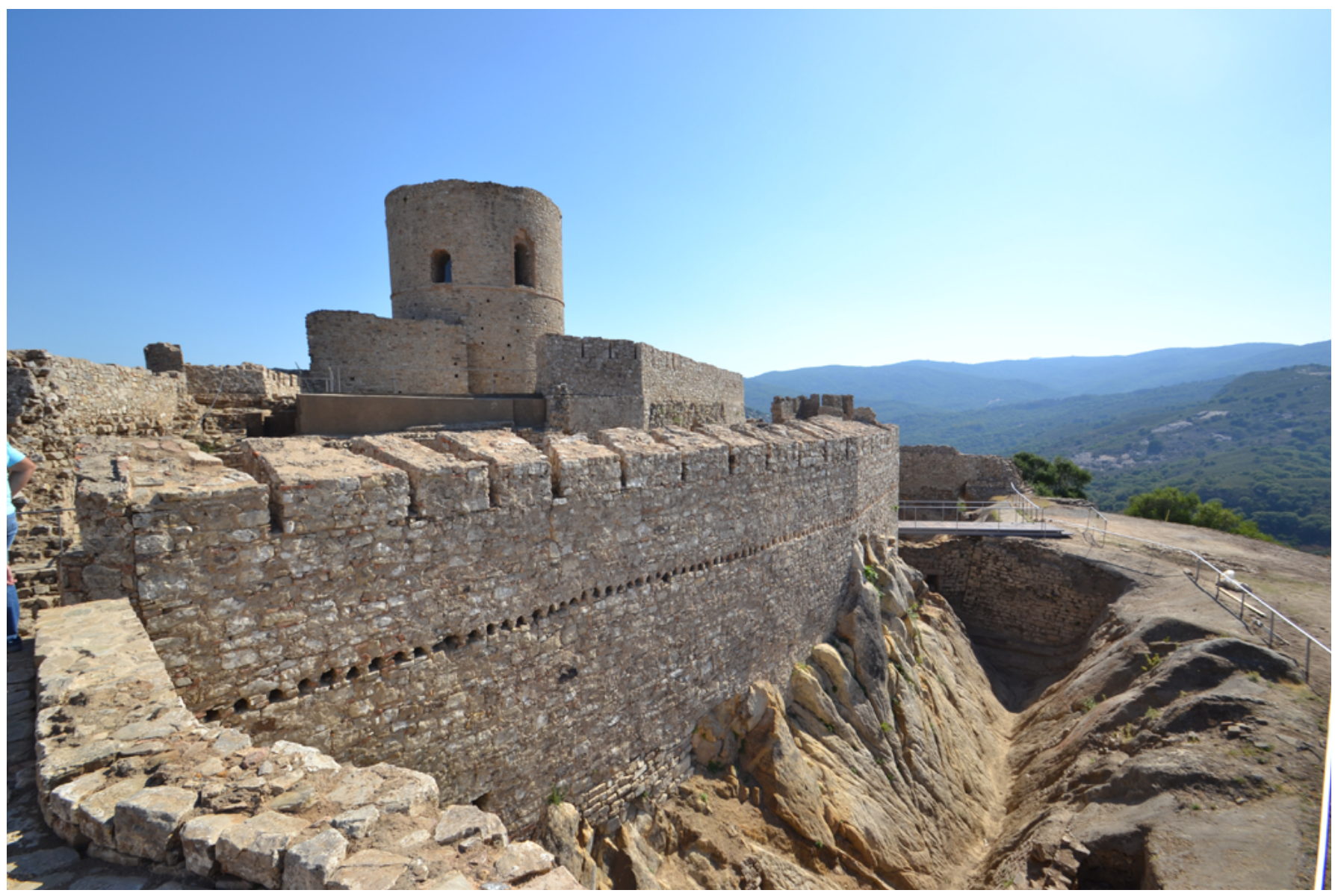




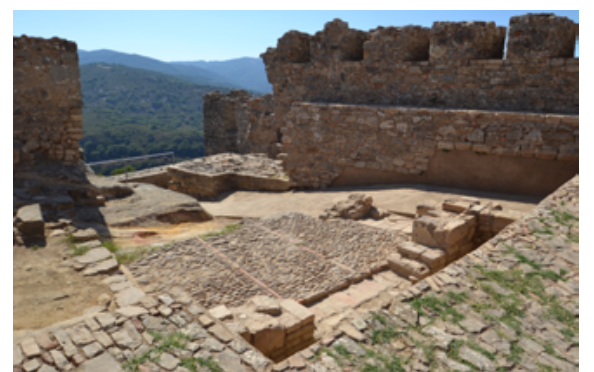

Pavimentos medievales y modernos (s. XIX) desde el patio de armas | foto Estudio Francisco Reina
En zonas con daños estructurales, se han realizado consolidaciones de fisuras y grietas mediante cosido con elementos de acero inoxidable y resina. Finalmente, se ha aplicado a todas las superficies una hidrofugación incolora, que tiene como objetivo frenar la entrada de agua en el interior de los muros y protegerlos de su acción degradadora.

$>$ En pavimentos, tras la aplicación de biocidas y una vez realizadas las labores de limpieza, fueron fijadas con mortero de cal las piezas sueltas. En las faltas o lagunas se ejecuta una superficie neutra mediante mortero de cal coloreado con tierras y acabado rugoso, dispuesta a bajo nivel para simular la base o cama del pavimento. En casos de restitución, las nuevas aportaciones se distinguen ligeramente por la disposición ordenada de sus piezas en contraste con los tramos conservados, criterio que permite que una mirada atenta las pueda distinguir.

$>$ Para las nuevas carpinterías, se han planteado materiales que tuvieran un buen envejecimiento natural y, por tanto, reducido mantenimiento. En las puertas se ha empleado acero corten combinado con madera natural tratada al aceite, con un sencillo despiece. En los ventanales de la torre ha primado la voluntad de liberar al máximo el hueco existente y hacer invisible la nueva carpintería, por lo que se ha proyectado un marco mínimo en acero inoxidable mate.

Por su singularidad, se describen los trabajos específicos realizados en la puerta del Reloj y en la torre del Homenaje del Alcázar:

$>$ En la puerta del Reloj (s. XII-XV) destaca la recuperación de los restos de esgrafiados y decoración pictórica (sebka) pertenecientes a la puerta de la medina de Xemina, así como la restauración de lápidas e inscripciones romanas reutilizadas existentes en las jambas.

$>$ Los revestimientos con decoraciones fueron documentados fotográficamente y fue estudiada su composición geométrica. Una vez solucionadas las humedades procedentes del muro soporte mediante la impermeabilización de un tramo del paso de ronda, se ha ejecutado una cuidadosa limpieza -tanto mecánica (cepillado suave) como química- sobre los sectores conservados para evitar eliminar pátinas, precedida de un tratamiento biocida por impregnación de toda la superficie. Se inyectaron polímeros acrílicos y se reintegraron las juntas. Se ha realizado una restitución geométrica selectiva del dibujo, diferenciando levemente las partes conservadas de los añadidos y aplicándose finalmente un tratamiento de hidrofugación.

En las aras romanas reutilizadas en las jambas de la puerta, se realizó un tratamiento biocida por impregnación de toda la superficie, que se dejó actuar un periodo de tiempo. Las zonas desprendidas o exfoliadas fueron fijadas con inyecciones de mortero. La limpieza mecánica se realizó con cepillo suave y escalpelo, evitando eliminar pátinas y manteniendo cierta oscuridad 


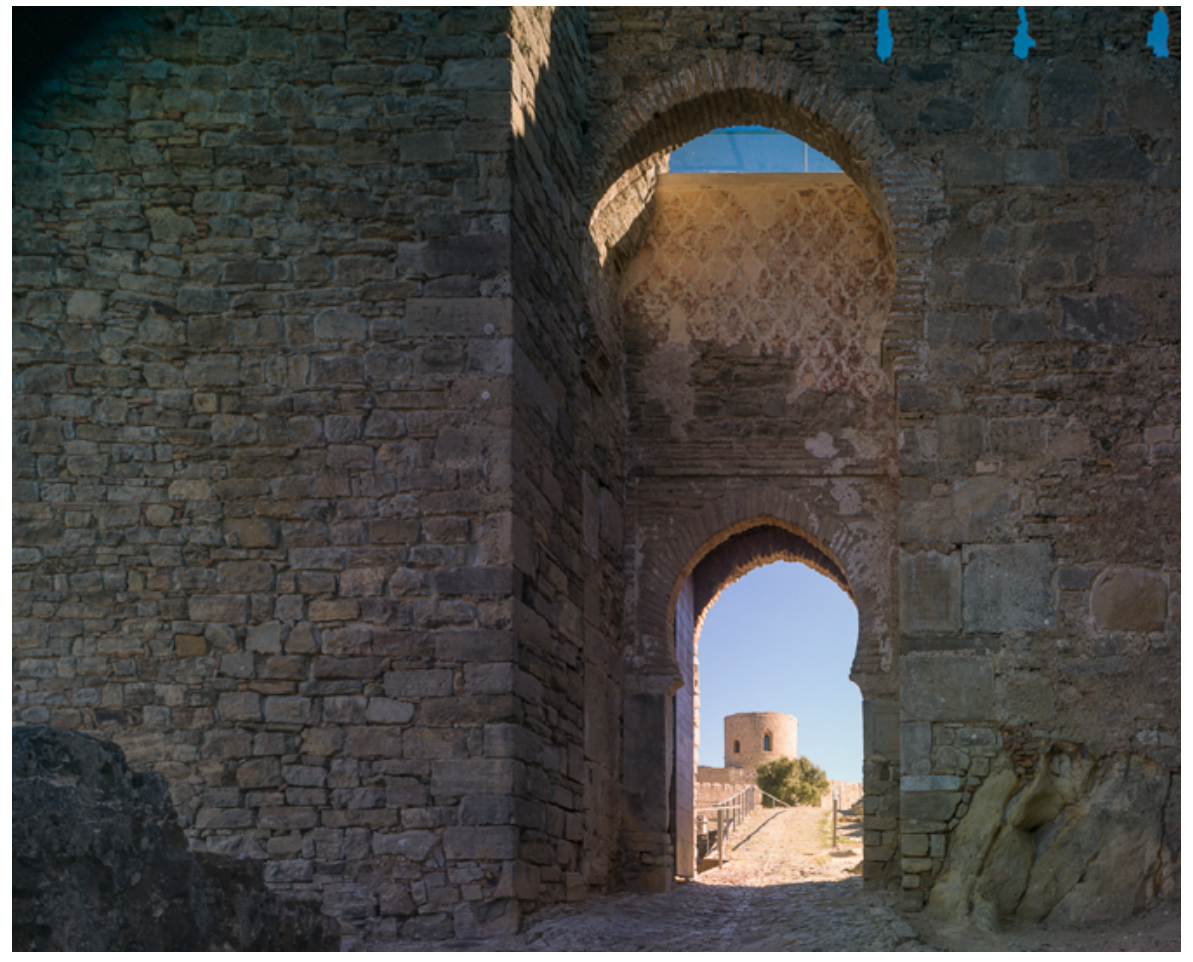

en las incisiones de las letras grabadas al objeto de facilitar su lectura. Al igual que el resto de fábricas, se aplicó un tratamiento final de hidrofugación.

$>$ En el recinto del Alcázar y la torre del Homenaje ha tenido un especial interés la recuperación y tratamiento de los niveles y pavimentos históricos que se conservaban en su mayor parte, confiando en facilitar la lectura de las secuencias definidas por pasos, recintos y plataformas. En el acceso en acodo, delimitado por las murallas medievales, se consolidan y delimitan los pertenecientes a la fase bajomedieval cristiana (S. XV-XVI) descubiertos en una campaña anterior de investigación. En cambio, en la plataforma o recinto superior -ámbito de la torre, transformado en un patio de armas durante la Guerra de la Independencia- se consolidan y restituyen parcialmente los pavimentos del s. XIX. En el extremo meridional del alcázar, la ausencia de la muralla de cierre ha permitido habilitar un punto de paso hacia los nuevos recorridos de visita extramuros. De este modo, la visita actual dispone de un doble recorrido -externo e interno- que queda enlazado con naturalidad a través de esta falta. El puente del foso, acceso histórico al Alcázar, se restaura y se evidencian mediante limpieza arqueológica los restos conservados del camino.

La torre del Homenaje ha sido objeto de una actuación integral -consolidación estructural, restauración y reposición de pavimentos, restauración de
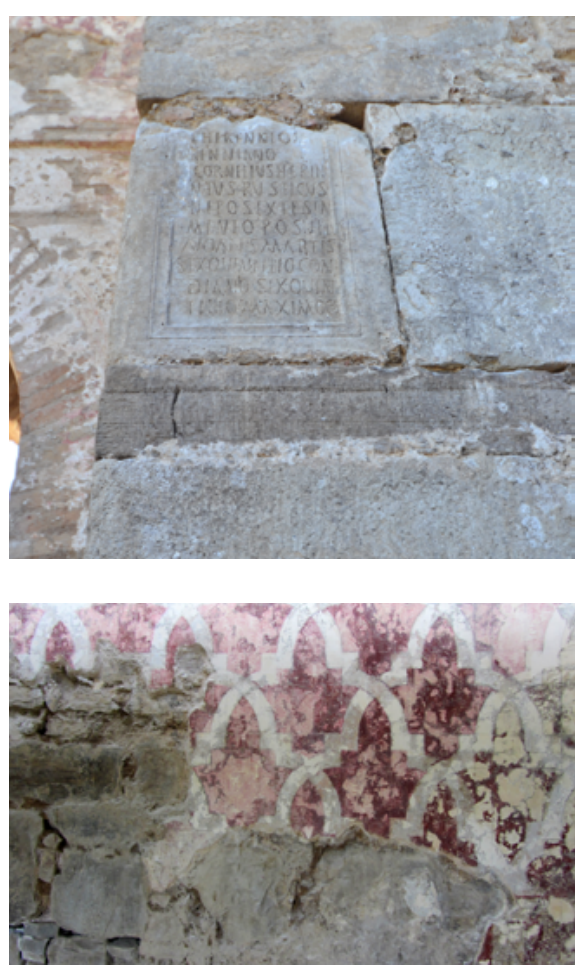

A la izquierda, vista de la puerta del Reloj tras los trabajos de restauración | foto Jesús Granada

A la derecha, detalles en la puerta del reloj de las aras romanas y decoraciones islámicas tras los trabajos de restauración | fotos Estudio Francisco Reina 

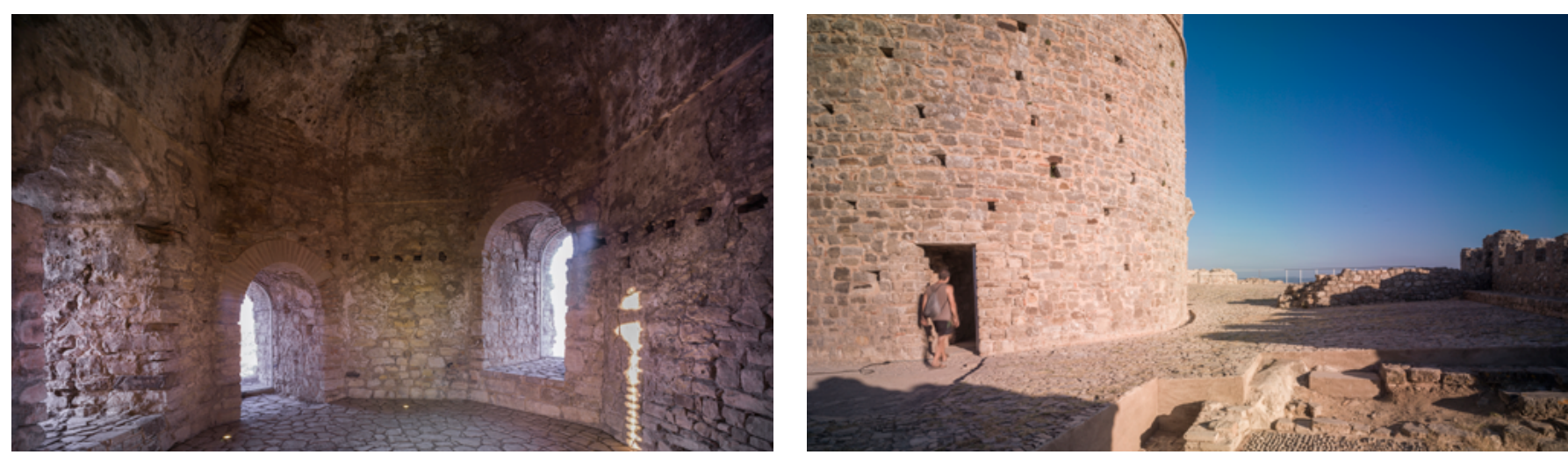

Alcázar, torre del Homenaje. A la izquierda, interior de la cámara principal | fotos Jesús Granada

fábricas y revestimientos originales, carpinterías, iluminación interior- habilitándose el acceso público a todos sus niveles incluida la cubierta, desde donde el visitante puede apreciar el alto valor estratégico del castillo. En relación con los accesos, se habilita el situado en la planta inferior, previa consolidación superficial de las fábricas de mampostería. Esta actuación ha supuesto también la recuperación del pavimento exterior inmediato (de tierra y cal) y la colocación de una puerta. Se ha procedido al cegamiento del hueco existente en la planta intermedia (abierto en el s. XIX), lo que ha mejorado la percepción masiva y monolítica de la torre, al apreciarse únicamente los huecos medievales originales situados en el nivel superior.

En relación con los pavimentos, en el nivel inferior se ejecuta una superficie continua de mortero de cal y arena seleccionada que presenta un acabado similar a los restos de mortero base preexistentes (y que posiblemente fuera originalmente soporte de algún material cerámico que no se ha conservado). En plantas primera y segunda, se reparan y restituyen los pavimentos de losas irregulares de piedra caliza colocados en el s. XIX que han aparecido bastante completos tras la limpieza practicada. En planta de cubierta, dado el interés de los hallazgos, se deja a la vista el pavimento de mortero de cal del s. XVI que reviste la bóveda del cuerpo alto, así como las huellas de los apoyos del entarimado de madera ejecutados durante el s. XIX. Para evitar posibles entradas de agua en los huecos existentes, éstos han sido cegados mediante tramos de pilares de madera que sobresalen levemente para significar en planta los límites de la plataforma artillera.

\section{FUTURAS FASES DE RESTAURACIÓN}

Aunque las limitaciones económicas redujeron el alcance de esta primera fase al sector oriental, la propuesta de partida -más ambiciosa- tenía como objetivos la valoración de los accesos históricos, tanto el este, a través de la Sección torre del Homenaje | plano estudio Francisco Reina 
extensión al yacimiento mozárabe situado extramuros, así como evidenciar la importancia que tienen las distintas infraestructuras hidráulicas conservadas en el entendimiento del complejo.

Retomando este planteamiento, se propone que una segunda fase se centre en el sistema defensivo y de accesos del sector occidental, la recuperación de los aljibes medievales y el acondicionamiento del entorno de la iglesia de la Misericordia asociado a la visita al castillo. Una fase posterior, acometería la intervención en el sector norte del sistema amurallado -entorno inmediato al actual cementerio- cerrando de este modo el perímetro. En paralelo, mediante el desarrollo de un proyecto general, se plantearía de manera sistemática la investigación integral del complejo mediante un programa de excavaciones y estudios que afectarían tanto al espacio intramuros como al entorno.

En relación con el sector occidental, significar que los trabajos realizados en 2002 y posteriormente las excavaciones de 2004 sacaron a la luz los res-

Fases de actuación contempladas en el Programa Director | plano Estudio Francisco Reina

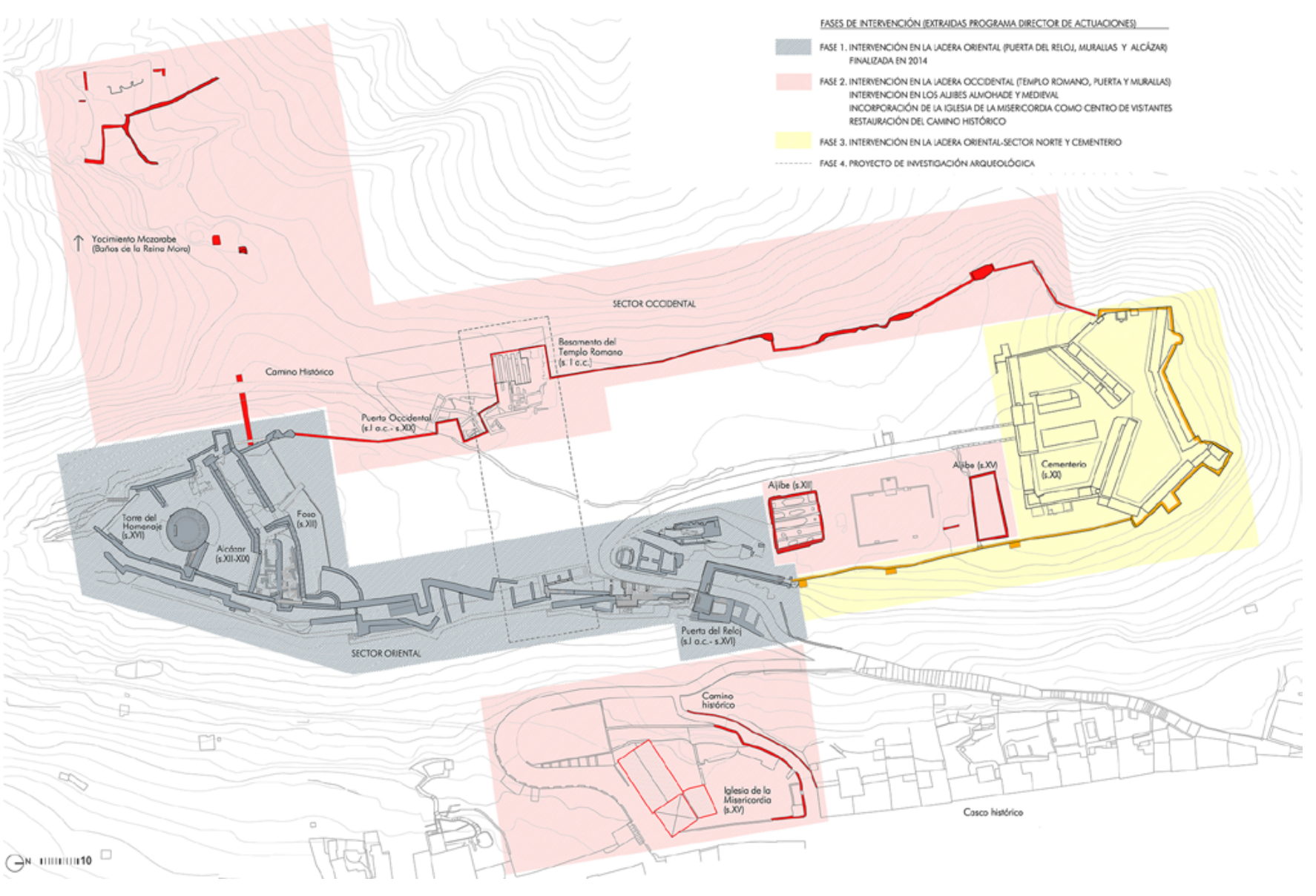


Aljibe islámico situado en el interior del recinto amurallado | foto Jesús Granada

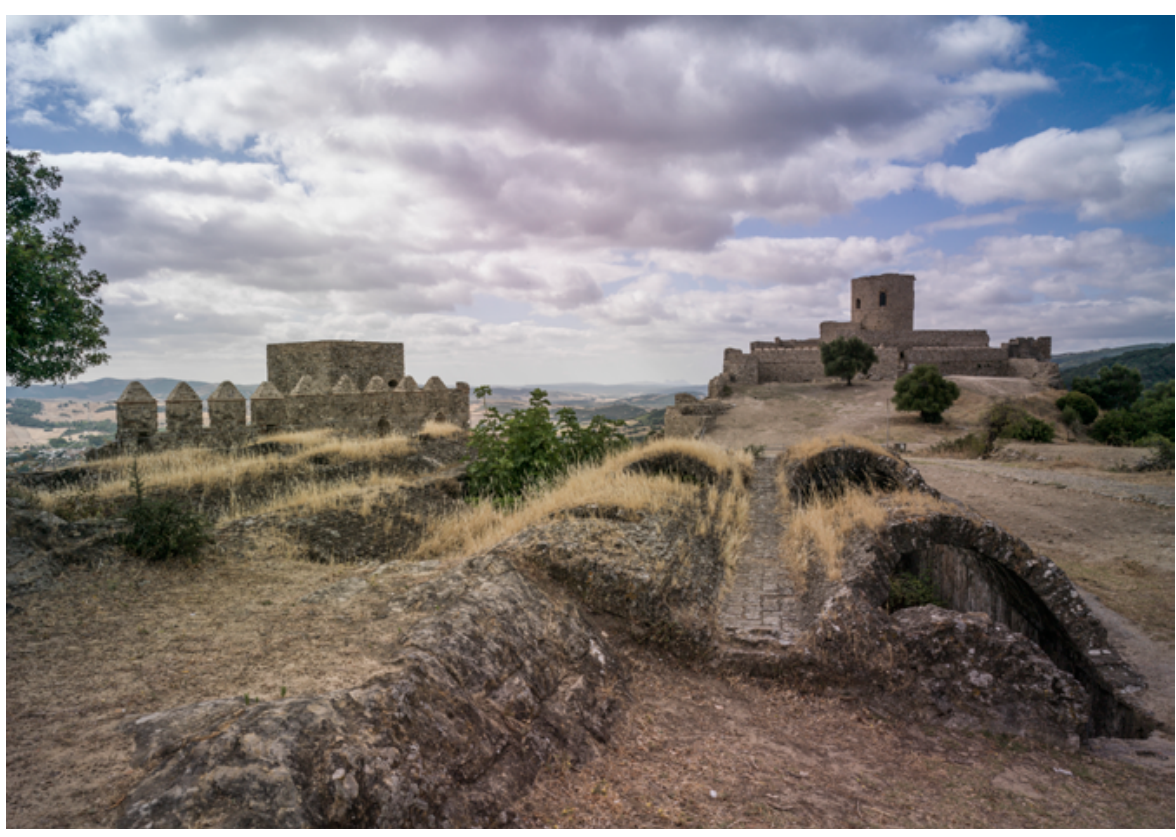

tos de una estructura arquitectónica romana de notable relevancia, el basamento de un templo tetrástilo próstilo integrado en la muralla dominando el acceso principal de la ciudad de Oba, donde el paisaje del parque natural de Los Alcornocales se hace más presente, probablemente el hallazgo de la historia arqueológica del castillo. La recuperación y contextualización de sus estructuras requieren intervenir sobre su entorno inmediato: el frente amurallado -conservado a lo largo de cien metros con un alzado prácticamente inalterado y de cierta entidad-, la puerta y el camino original de acceso a Oba -cuyos restos se reconocen en diversos puntos de la ladera occidentalasí como el inicio de la trama urbana intramuros.

Esta actuación dotaría a la visita al castillo de un contrapunto histórico necesario al implementar con el mundo romano un conjunto actualmente escorado en las laderas oriental y alcázar hacia períodos medievales y postmedievales. Sería deseable que la actuación permitiera contextualizar los asentamientos situados extramuros: la ciudad romana, los arrabales medievales y el yacimiento mozárabe.

Los aljibes situados en el interior del antiguo recinto amurallado reúnen valores excepcionales desde los puntos de vista espacial e histórico y representan cada uno un momento del abastecimiento hidráulico de la población; en el caso del aljibe islámico, su responsabilidad en el servicio a la ciudad de Xemina es esencial por su centralidad y dimensiones. En el caso del más moderno, por su protagonismo en el suministro a la ciudad de Jimena una vez abandonado el recinto. La tradición historiográfica vincula el aljibe islámico 
con el período almohade (s. XII y XIII) debido a que su excelente estado de conservación permite reconocer un sistema de arcadas con arcos de entibo a montacaballo muy similar a los del acueducto sevillano de los caños de Carmona, atribuidos al arquitecto Ibn Hayyay, oriundo de la vecina Gebel el Tarik (Gibraltar). Es esta una especulación basada en criterios analógicos que debería contrastarse mediante metodología arqueológica. En la actualidad los escombros llenan algo más de la mitad de su espacio si bien las excavaciones realizadas en 2002 permitieron localizar su suelo original, perfectamente conservado. Aunque parte del sistema definido por esta estructura ha desaparecido, su recuperación permitiría establecer una conexión lógica con el pozo-mina adyacente, recuperado en la fase recientemente ejecutada.

La rehabilitación de la iglesia de la Misericordia y su entorno facilitaría la gestión y logística del yacimiento. Desde el punto de vista científico las obras a emprender permitirían conocer a fondo su cronología y evolución y sobre todo su vinculación con el primer intento de urbanismo extramuros, claro a partir del siglo XV, escasamente estudiado en la historia de Jimena. Se valora la recuperación del camino histórico que delimita las huertas hacia el norte y la incorporación de sus distintos ámbitos para el acondicionamiento de espacios de acogida, descanso e información previa a la visita al castillo.
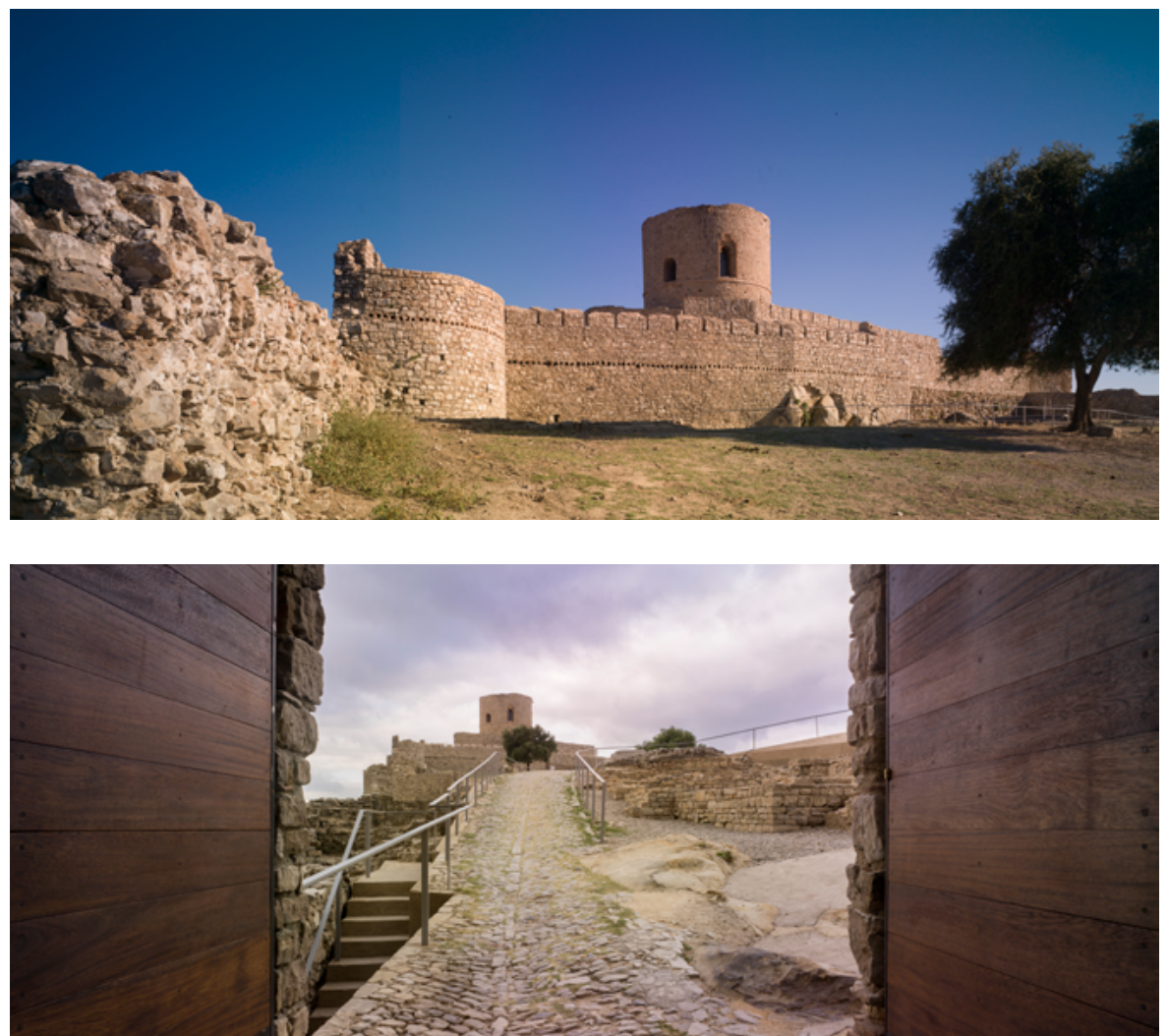

Vista del alcázar tras los trabajos de restauración de 1. ${ }^{a}$ fase | foto Jesús Granada 
FICHA TÉCNICA. INTERVENCIÓN EN EL CASTILLO DE JIMENA DE LA FRONTERA (CÁDIZ). FASE I-SECTOR ORIENTAL

\section{Promotor:}

Obra: Ayuntamiento de Jimena / Ministerio de Fomento

(Financiación a través del Programa 1\% Cultural)

Redacción de proyecto y dirección facultativa: Consejería de Educación, Cultura y Deporte, Junta de Andalucía

\section{Autor del proyecto:}

Francisco Reina Fernández-Trujillo, arquitecto (www.reina-asociados.com)

Colaboradores:

Mercedes Sánchez González, Olga Valderas Grisalvo, José Allona Rosendo, arquitectos

Pedro Lobato Vida, cálculo de estructuras

Manuel Ponce Fernández, instalaciones

Dirección facultativa de las obras:

Francisco Reina Fernández-Trujillo, arquitecto

Francisco Alcoba González, arquitecto técnico

Coordinación de intervención arqueológica:

Miguel Ángel Tabales Rodríguez, arqueólogo

Intervención arqueológica:

Raquel Utrera Burgal (dirección) y Juan Miguel Pajuelo Sáez (co-dirección), arqueólogos

Restauración (puerta del Reloj):

Carlos Núñez Guerrero (Dédalo Bienes Culturales S.L.)

Empresa constructora:

Azuche $88 \mathrm{~S}$. L.

Fecha de inicio/final de obra:

4 de mayo de 2012 / 23 de julio de 2014

Presupuesto general:

1.017.241,38€

Superficie del área de intervención:

$5.125 \mathrm{~m}^{2}$

Fotografías:

Jesús Granada, Estudio Francisco Reina, Miguel Ángel Tabales, Carlos Núñez 


\section{BIBLIOGRAFÍA}

- AA. VV. (1984) Historia de los Pueblos de la provincia de Cádiz. Jimena de la Frontera. Cádiz: Diputación de Cádiz, 1984

- Alfageme RUANO, P. (1978) El castillo de Jimena de la Frontera. Archivo hispalense: Revista histórica, literaria y artística, tomo $61,{ }^{\circ}{ }^{\circ} 186,1978$, pp. 151-178

- BUENO LOZANO, M. (1989) Significado del nombre de Jimena y su aparición en la Historia. Almoraima, n. ${ }^{\circ}$ 2,1989

- BUENO LOZANO, M. (1993) La frontera entre Jimena y Alcalá de los Gazules. Almoraima, n. ${ }^{\circ}$ 9, 1993

- Bueno LOzANo, M. (1998) Las dos visitas de Enrique IV, rey de Castilla y León, a Jimena de la Frontera. Almoraima, $\mathrm{n} .{ }^{\circ} 20,1998$

- BARRoso RUIZ, C. (1978) Nuevas pinturas del abrigo Cueva de la Laja Alta. Jábega, n. ${ }^{\circ} 24,1978$

- BARRoso RUIZ, C. (1980) Nuevas pinturas rupestres en Jimena de la Frontera (Cádiz): Abrigo de la Laja Alta. Zephyrus: Revista de prehistoria y arqueología, n. ${ }^{\circ} \mathrm{XXX}$ XXXI, 1980, pp. 23-42

- GARÓFANO SÁNCHEZ, R. (2005) Gibraltar, sur de España y Marruecos en la fotografía victoriana de G. W. Wilson \& Co. Cádiz: Fundación Provincial de Cultura, Diputación de Cádiz, 2005 (Catálogo de la exposición)

- HUARTE CAMBRA, R. (2005) Análisis históricoestratigráfico de los materiales cerámicos del Castillo de Jimena de la Frontera (Cádiz). Anuario Arqueológico de Andalucía 2002, vol. 3, tomo 1, 2005 (Actividades de urgencia), pp. 119-130

- NÚÑEZ GUERRERO, C. (2014) Informe de las actuaciones de conservación y restauración realizadas en la Portada de la Torre del Reloj del Castillo de Jimena de la Frontera, Cádiz (documento inédito)

- PÉRez GARcíA, P. A. (1976) Oba: Jimena de la Frontera, Evolución Histórica. Cádiz: Diputación, 1976

- PUERTAS TRICAS, R. (1982) Excavaciones arqueológicas en Lacipo (Casares, Málaga): campañas de 1975 y 1976. Madrid: Dirección General de Bellas Artes y Archivos, 1982 (Serie Excavaciones Arqueológicas en España, n. $\left.{ }^{\circ} 125\right)$

- REgUEIRA RAMOS, J.; REgUEIRA MAURIZ, E.; MENA TORRES, M. A. (1988) Jimena y su castillo. Cádiz: ALBA S. A., 1988

- REINA FERNÁNDEZ-TRUJILLO, F. J.; TABALES RODRÍGUEZ, M. A. (2005) Una estrategia de intervención arqueológica de apoyo a la rehabilitación en el Castillo de Jimena de la Frontera. En SÁNCHEZ DE LAS HERAS, C.; PÉREZ IRIARTE, L.; RODRIGO VILA, S. (coord.) LoS castillos: reflexiones ante el reto de su conservación. Actas de las Jornadas, Alcalá la Real, 26 al 28 de mayo de 2004. Sevilla: Junta de Andalucía, Consejería de Cultura, 2005, pp. 197-215

- REINA FERNÁNDEZ-TRUJILLO, F. J.; TABALES RODRÍGUEZ, M. A. (2006) Castillo de Jimena de la Frontera: descripción de una estrategia de intervención. PH Boletín del Instituto Andaluz del Patrimonio Histórico, n. ${ }^{\circ} 60,2006$, pp. 152-169

- ROLDÁN GÓMEZ, L. (1992) Técnicas constructivas romanas en Carteia (San Roque, Cádiz). Madrid: Universidad Autónoma, 1992 (Monografías de Arquitectura Romana, 1)

- $\quad$ ROLDÁN GÓMEZ, L. (1993) Técnicas arquitectónicas en la Bética romana. Madrid: Universidad Autónoma, 1993

- SÁNCHEZ SAUS, R. (1982) Jimena (1431-1451): Avanzada de Castilla en la Frontera. Estudios de Historia y Arqueología Medievales, n. ${ }^{\circ}$ II, 1982, pp. 19-29

- SASSON, H. Una posible iglesia mozárabe en Jimena de la Frontera (Cadiz). Almoraima: revista de estudios campogibraltareños, n. ${ }^{\circ} 17,1997$, pp. 99-106

- SASSON, H. (2001a) Oba Romana. Algeciras: Editorial Regueria, 2001 (Colección El Castillo de Jimena; n. ${ }^{\circ}$ 8)

- SASSON, H. (2001b) Romanos y moros en las afueras de Jimena de la Frontera. Nuevos descubrimientos. Almoraima: revista de estudios campogibraltareños, $\mathrm{n} .{ }^{\circ} 25$, 2001, pp. 141-148

- SASSON, H. (2003) Hacia la datación del castillo de Jimena de la Frontera. El aljibe central. Almoraima: revista de estudios campogibraltareños, n. ${ }^{\circ} 29,2003$, pp. 213-218

- SCHUBART, H. (1993) Investigaciones geológicas y arqueológicas sobre la relación costera de los asentamientos fenicios en la Andalucía mediterránea. En ALVAR, J.; BLÁZQUEZ, J. M. (ed.) Los enigmas de Tarteso. Madrid: Cátedra, 1993, pp. 69-80

- TABALES RODRÍGUEZ, M. A. (2002) Sistema de análisis arqueológico de edificios. Sevilla: Universidad, 2002

- tabales RodRíguez, M. A.; Oliva MUÑoz, P.; MORA VICENTE, G. et ál. (2005) Investigaciones arqueológicas en el Castillo de Jimena de la Frontera. Cádiz. Fase I. (2002). Anuario Arqueológico de Andalucía 2002, vol. 3, tomo 1, 2005 (Actividades de urgencia), pp. $131-155$

- TABAles RodRíguez, M. A.; PAJUElo SÁEZ, J. M.; UTRERA BURGAL, R. M. (2003) Investigaciones arqueológicas en el castillo de Jimena de la Frontera. Fase II (2003) (documento inédito)

- TABAlES RODRígueZ, M. A. (2004) Excavaciones 
arqueológicas en el castillo de Jimena de la Frontera (Cádiz). Intervención de apoyo a la restauración en la alcazaba sur, 2004 (documento inédito)

- TABAles ROdRígueZ, M. A (2006) Programa de Investigaciones Arqueológicas en el castillo de Jimena de la Frontera (Cádiz). Almoraima: revista de estudios campogibraltareños, n. ${ }^{\circ} 33,2006$, pp. 9-30

- TABAlES RODRÍGUEZ M. A.;, PAJUELO SÁEZ, J. M.; UTRERA BURGAL R. M. (2007) Investigaciones arqueológicas en el castillo de Jimena de la Frontera. Fase $V, 2007$ (documento inédito)

- TABALES RODRÍGUEZ M. A.; VARGAS LORENZO, C. (2011) Análisis arqueológico parcial. Torre del homenaje del castillo de Jimena de la Frontera (2011) (documento inédito)

- TORREMOCHA SILVA, A.; SÁEZ RODRÍGUEZ, A. (1996) Fortificaciones islámicas en la orilla norte del Estrecho. En AA. VV. Actas del primer congreso internacional de fortificaciones en Al-Andalus (Ageciras, noviembre-diciembre, 1996). Algeciras: Fundación Municipal de Cultura José Luis Cano, 1998

- UTRERA BURGAL R. M.; PAJUELO SÁEZ, J. M. (2013) Resumen y resultados de la intervención arqueológica preventiva, control de movimientos de tierra, para la restauración del Castillo de Jimena de la Frontera, Cádiz. Fase I, sector oriental (2013) (documento inédito)

- VALVERDE, M. J. (1996) La prematura conquista de la fortaleza de Jimena en 1431 y su vinculación al cabildo de Jerez. Estudios de Historia y Arqueología medievales, n. ${ }^{\circ}$ XI, 1996, pp. 217-242

- VARGAS-MACHUCA GARCÍA, T. (1973) Oba (Jimena de la Frontera en la Época Romana). Ceuta: Instituto de Estudios Ceutíes, 1973 